\title{
Engineering of Semiconductor Nanocrystals for Light Emitting Applications
}

\author{
Francesco Todescato ${ }^{1, \dagger}$, Ilaria Fortunati ${ }^{1, \dagger}{ }^{,}$Alessandro Minotto ${ }^{1}$, Raffaella Signorini ${ }^{1}$, \\ Jacek J. Jasieniak ${ }^{2}$ and Renato Bozio ${ }^{1, *}$ \\ 1 Department of Chemical Science and U.R. INSTM, University of Padova, Via Marzolo 1, Padova I-35131, \\ Italy; ftodescato@yahoo.it (F.T.); ilaria.fortunati@unipd.it (I.F.); minotto.ale@gmail.com (A.M.); \\ raffaella.signorini@unipd.it (R.S.) \\ 2 Department of Materials Science and Engineering, Monash Energy Materials and Systems Institute (MEMSI), \\ Monash University, 22 Alliance Lane, Room 109, Clayton 3800, Australia; Jacek.Jasieniak@monash.edu \\ * Correspondence: Renato.bozio@unipd.it; Tel.: +39-049-8275681 \\ + These authors contributed equally to this work.
}

Academic Editor: Jang-Kun Song

Received: 28 May 2016; Accepted: 2 August 2016; Published: 9 August 2016

\begin{abstract}
Semiconductor nanocrystals are rapidly spreading into the display and lighting markets. Compared with liquid crystal and organic LED displays, nanocrystalline quantum dots (QDs) provide highly saturated colors, wide color gamut, resolution, rapid response time, optical efficiency, durability and low cost. This remarkable progress has been made possible by the rapid advances in the synthesis of colloidal QDs and by the progress in understanding the intriguing new physics exhibited by these nanoparticles. In this review, we provide support to the idea that suitably engineered core/graded-shell QDs exhibit exceptionally favorable optical properties, photoluminescence and optical gain, while keeping the synthesis facile and producing QDs well suited for light emitting applications. Solid-state laser emitters can greatly profit from QDs as efficient gain materials. Progress towards fabricating low threshold, solution processed DFB lasers that are optically pumped using one- and two-photon absorption is reviewed. In the field of display technologies, the exploitation of the exceptional photoluminescence properties of QDs for LCD backlighting has already advanced to commercial levels. The next big challenge is to develop the electroluminescence properties of QD to a similar state. We present an overview of QLED devices and of the great perspectives for next generation display and lighting technologies.
\end{abstract}

Keywords: quantum dots; display; photoluminescence; laser emission; electroluminescence; LED

\section{Introduction}

Liquid crystal displays (LCD) and organic light emitting diodes (OLED) are the two major technologies competing within the $\$ 100$ bn display market [1], each with its own advantages and disadvantages. LCD is leading in lifetime, power consumption, resolution density and cost; comparable to OLED in ambient contrast ratio and viewing angle, but inferior in such fundamental requirements as color and brightness, module thickness / flexibility and response time [1-3].

The recent implementation of nanocrystalline quantum dots (QDs) for the backlighting of LCD displays has provided a competitive advantage over OLED. Thanks to their intrinsic optical properties, such as their broad absorption band but narrow emission spectra, high fluorescence quantum yield, high photostability and controllable emission and surface properties [4-6], QD based down-conversion displays are now showing performances comparable or even better than OLED devices. QDs enable highly saturated colors, a wider color gamut and a comparable response time, while retaining advantages in cost, resolution, optical efficiency and durability. For display applications, QDs can be 
used either exploiting their photoluminescence for LCD backlight unit or their electroluminescence for QD-light emitting diodes (QLED). In fact, advances in this display technology are expected from the development of QD-based light emitting diodes (QLED) currently underway [7,8].

This remarkable progress has been made possible by the rapid advances in the synthesis of colloidal QDs and by the progress in understanding the intriguing new physics exhibited by these nanoparticles and how it relates to their structure $[9,10]$. In the last few decades wet synthesis strategies have achieved an enormous progress in producing a great variety of colloidal nanostructures with controlled chemical and physical properties. Indeed, semiconductor nanocrystals (NCs), consisting of between 100 and 10,000 atoms, can now be readily synthesized with unprecedented control of size (1-10 nanometers), distribution ( $<10 \%$ polydispersity), shape (spherical, elongated, branched, hollow, etc.) and composition (e.g., IV, II-VI, I-III-VI, I-II-IV-VI grouped material). Of all the underlying phenomena that are demonstrated at the nanoscale, the quantum size effect is arguably the most important. It occurs when the physical dimensions of a NC become smaller than the characteristic lengths of the quantum states of charge carriers (electrons and holes) in the ground or in their excited states-a condition that is known as quantum confinement. The Coulomb attraction between oppositely charged carriers drives a spatial localization of bound electron-hole pairs, i.e., excitons. This phenomenon makes the optical absorption and emission properties of a given material size-dependent, with band peaks shifting to shorter wavelengths at smaller sizes [11-16].

It is well known that the optical absorption and emission properties of semiconductor quantum dots (QDs) depend on an intricate interplay of factors, beside their chemical composition (whether elemental, II-VI, III-V, etc.), their dimensions and shape. The composition and chemistry of their surfaces and the defect distribution, whether at surfaces or interfaces, is of paramount importance. Furthermore, for practical applications QDs are used as ensembles and suffer from inherent polydispersity factors. Unraveling this complexity to gain a complete understanding of the physical, optical and electrical properties of QDs has remained a difficult research challenge.

However, through progressive improvement in QD quality, largely enabled by a better understanding of the mechanisms for their synthesis and of the fundamental physical processes underlying their properties, significant progress has been made in achieving nearly ideal photophysical properties. Recent advances in nanostructure assembly have combined the spatial confinement of elementary excitations with the impressive design flexibility provided by self-assembly into 2D or 3D superstructures [17,18]. A set of inorganic components has been identified as distinct building blocks in order to design and fabricate specific systems suited for engineering energy transfer (ET) [19] and charge transfer (CT) [20] processes through systematic control on dimensionality, rate and flow direction in structures characterized by the combination of zero-dimensional systems, (e.g., quantum dots), one dimensional systems (wires, tubes and rods) and 2D systems (platelets) in solution. Multilayer nanostructures for QLED applications are indeed hybrid multifunctional systems in which QD layers are sandwiched between inorganic and/or organic layers for electron and hole transport [21].

For all these reasons, it has been possible to use QDs in lucrative applications ranging from biological labels [22], solar cells [23] and light emitting devices [24-26]. For such applications, QDs possess sufficiently strong light absorption properties and/or efficient and stable emission to be considered superior compared to molecular organic dyes. These features, including one- and two-photon absorption, are direct consequences of the quantum confinement effect and of the atom-like density-of-states of excitons at moderate energies above the bulk energy gap of the constituent semiconductor material. All the oscillator strength for optical transitions is concentrated at discrete energies that are strongly dependent on the size and shape of the QD. In this review, we will briefly investigate the QD physical features that can mainly affect the optical properties, in particular to increase their emission efficiency. In the second part, we will report some results regarding their practical use as active materials for optical gain applications and as light emitters in QLED and display devices. 


\section{Core/Shell Quantum Dots: What a Suitably Designed Shell Can Do}

In the most simplified picture, the electron $(e)$ and hole $(h)$ forming the exciton are just two oppositely charged particles trapped in the same nanometric volume [11]. The wavefunction distribution of both electrons and holes determines the strength of the Coulomb forces binding the $e-h$ pair. An efficient confinement is expected to enhance the overlap of wavefunctions, thus making the radiative decay rate very fast. This, combined with a reduced non-radiative decay due to exciton-phonon coupling [27], leads one to expect fluorescence quantum yield (QY) values approaching unity.

This ideal situation should be contrasted with the more complicated structural features and dynamical processes of a real QD. Roughly speaking, the deviation from ideal behavior can be traced back to two main categories of phenomena: (i) the presence of a large number of defects at the surface and/or within the QDs, which cause trapping of either electrons, holes, or both; and (ii) the activation of a very efficient non-radiative decay mechanism known as Auger recombination (AR) by the aforementioned charged defects or due to the presence of more than one exciton in a single QD [11].

Surfaces present a major fundamental challenge for QDs because, depending on their size, $\sim 10 \%-80 \%$ of all their atoms are located at the surface, where they remain only partially coordinated. These unsaturated surface dangling bonds act as efficient charge traps that drastically lower the QY [16].

The first strategy developed to saturate these dangling bonds is through organic passivation. In this process, a suitable organic ligand works as a capping agent for the surface atoms, while also providing the QD with solubility in a given solvent. Typical ligands include trioctylphospine (TOP), trioctylphospine oxide (TOPO), oleic-acid (OA) and various aliphatic amines (e.g., oleylamine, octylamine, etc.) $[9,16]$. Through the use of such passivants, the low QY of unpassivated QDs (commonly $<1 \%$ ) can be partially increased to typical values of between $1 \%$ and $50 \%$. However, in addition to providing limited chemical stability, one of the major caveats of organic passivation stems from steric hindrance, which reduces the surface packing density to below that required for complete surface coordination of the dots [28].

A more elegant solution that overcomes both of these limitations relies on the epitaxial growth of an inorganic shell layer around the core. A specific choice of core and shell materials may determine different electronic configurations depending on how the conduction band (CB) and valence band (VB) edges of bulk materials line up in the shell with respect to the core. In the so-called Type-I configuration the band edges of the shell encompass those of the core (see Figure 1a). This type of band alignment leads to the formation of potential barriers that effectively contain the extent of the $e$ an $h$ wavefunctions to within the core volume and away from the surface [11,13-15,29]. This property is also confirmed by the plot of the $e$ and $h$ radial probabilities reported in Figure 1a-right panel. Using Type-I core/shell QDs (for example: CdSe/CdS, CdSe/ZnS, InAs/CdSe), QYs up to unity have been achieved [30]. Compositional engineering of the core/shell structure can also favor preferential charge separation through a Type-II configuration (for example: CdTe/CdSe, CdSe/ZnTe, $\mathrm{InP} / \mathrm{CdS}$ ) [31-33] (see Figure 1b,c). Such a structure provides control of the spatial overlap between electrons and holes; thus, enabling a facile way to manipulate Coulomb interactions in nanostructures. This is important for developing efficient light emitting devices, non-linear optical applications and photovoltaics [29]. 


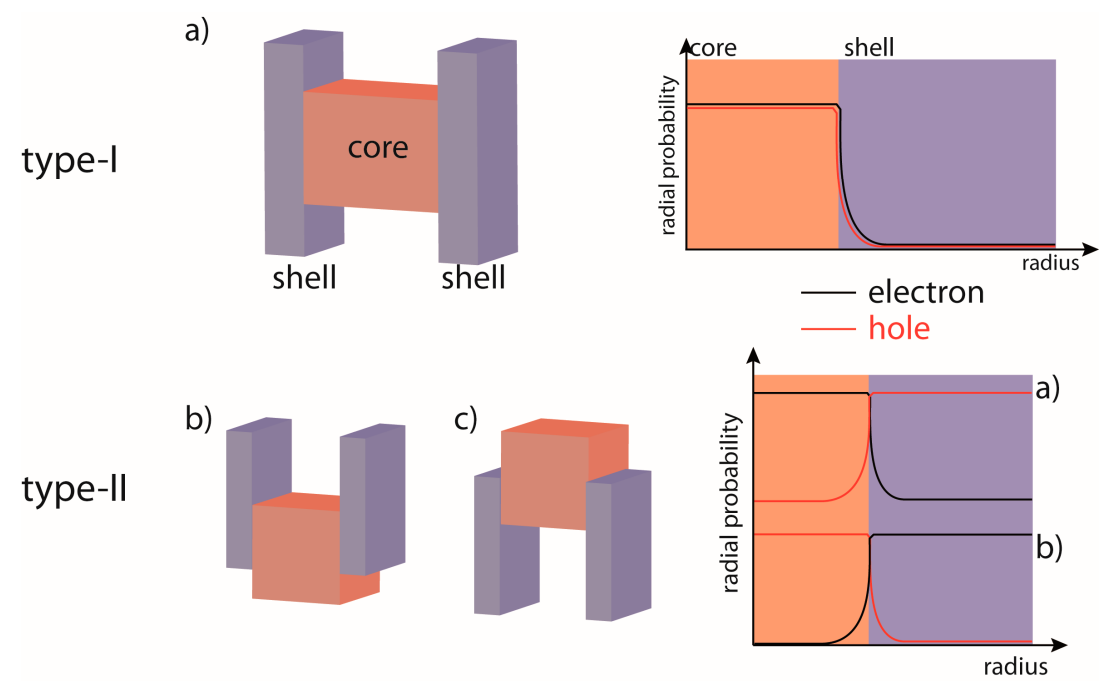

Figure 1. Schematic representation of band alignment and carriers distribution in Type-I (a) and Type-II QDs $(\mathbf{b}, \mathbf{c})$.

\section{Trends towards Type-II QDs for Energy Applications}

In contrast to Type-I nanocrystals, Type-II QDs exhibit strongly red-shifted emission (up to $\sim 150 \mathrm{~nm}$ ) originating from the radiative recombination of electron and hole across the core-shell interface, which would otherwise be impossible to achieve from either only core or only shell Type-I materials, or from giant QDs [34-36]. The emission wavelength can be tuned from 700 to $1000 \mathrm{~nm}$ by modifying the shell thickness and the core size. This large Stokes shift strongly reduces the self-reabsorption of emission, a process that generally worsens the conventional "phosphor" materials performances, giving new opportunities for the production of new generation light emitting devices [36]. In addition, among different shaped Type-II nanostructures, the fluorescence lifetimes of the CdSe/CdTe core/crown nanoplatelets are measured to be two orders of magnitude greater (up to $190 \mathrm{~ns}$ ) than those of the core-only Type-I nanoplatelets, thanks to the presence of the spatially indirect excitons at the Type-II interface [34,37].

Considering also the electronic properties of such nanostructures, quasi Type-II and Type-II QDs are highly promising materials as light harvesting materials for photovoltaic [38-40] and photoconduction applications, where efficient removal of excited charges is required. It has been demonstrated that heterostructures show higher photon to current conversion efficiency with respect to single-component QD, thanks to the ability to tailor the band offsets by selectively modifying the size of one constituent [32,33,41]. The poor stability, the difficult embedding in a high quality film of such nanostructures (in particular asymmetric ones) and the demanding physical charge extraction from the core, are the main challenging issues to be addressed to increase their large use in practical devices [42].

\section{Synthesis Strategy and Structural Characterization}

\subsection{Nanocrystal Synthesis Strategies}

The precise control of the electron and hole spatial distributions within QDs through tailored inorganic core/shell heterostructures, provides the required tuning of optical, electronic and chemical properties to be suitable for a wide range of potential applications. The origin of core/shell structures in colloidal systems stems from the pioneering work of Henglein and Brus in the 1980s. In particular, Henglein showed that the chemisorption of inorganic ions on semiconductor crystallites has drastic influences on the resulting photoluminescence (PL) properties [43]. Brus made use of this factor to be the first in reporting the growth of a $\mathrm{ZnS}$ monolayer (ML) around a CdSe core [44]. The low 
temperatures utilized in such syntheses gave rise to low QY $(<1 \%)$, due to the defective core, core/shell interface and poor passivation of the exterior surface dangling bonds. Following the advent of the hot-injection method in 1993 by Murray and co-workers to grow high quality II-VI QD cores [45], in 1996 Hines and Guyot-Sionnest used organometallic precursors to grow a $0.6 \mathrm{~nm} \mathrm{ZnS}$ shell on high quality CdSe colloidal QDs. They achieved unprecedented QYs of up to 50\% [46]. In close succession, detailed studies of $\mathrm{CdSe} / \mathrm{ZnS}$ and $\mathrm{CdSe} / \mathrm{CdS}$ growth were reported by the groups of Bawendi [47] and Alivisatos [48], highlighting the influence of shell composition and thickness on the extent of carrier delocalization and postulating on the importance of interfacial core/shell lattice strain.

Of all the synthetic methods used for the growth of core/shell QDs, the successive ion layer adsorption and reaction (SILAR) protocol developed by Li et al. has been the most versatile [49]. Borrowing from the concepts used in molecular beam epitaxy, SILAR relies on the separate introduction and growth of individual shell precursors monolayer by monolayer. As demonstrated for CdSe/CdS in Figure 2, this control has enabled highly precise QD heterostructures to be grown in a predictable manner [50]. Moreover, its versatility has been exploited for the synthesis of a wide variety of core/shell heterostructures, including CdSe/CdS/ZnS graded QDs [51], ultra-thick shell CdSe/CdS QDs (up to $20 \mathrm{ML}$ shell) [52], CdS/CdSe/CdS QD-quantum wells [53], and CdTe/CdSe Type-II QDs [54].

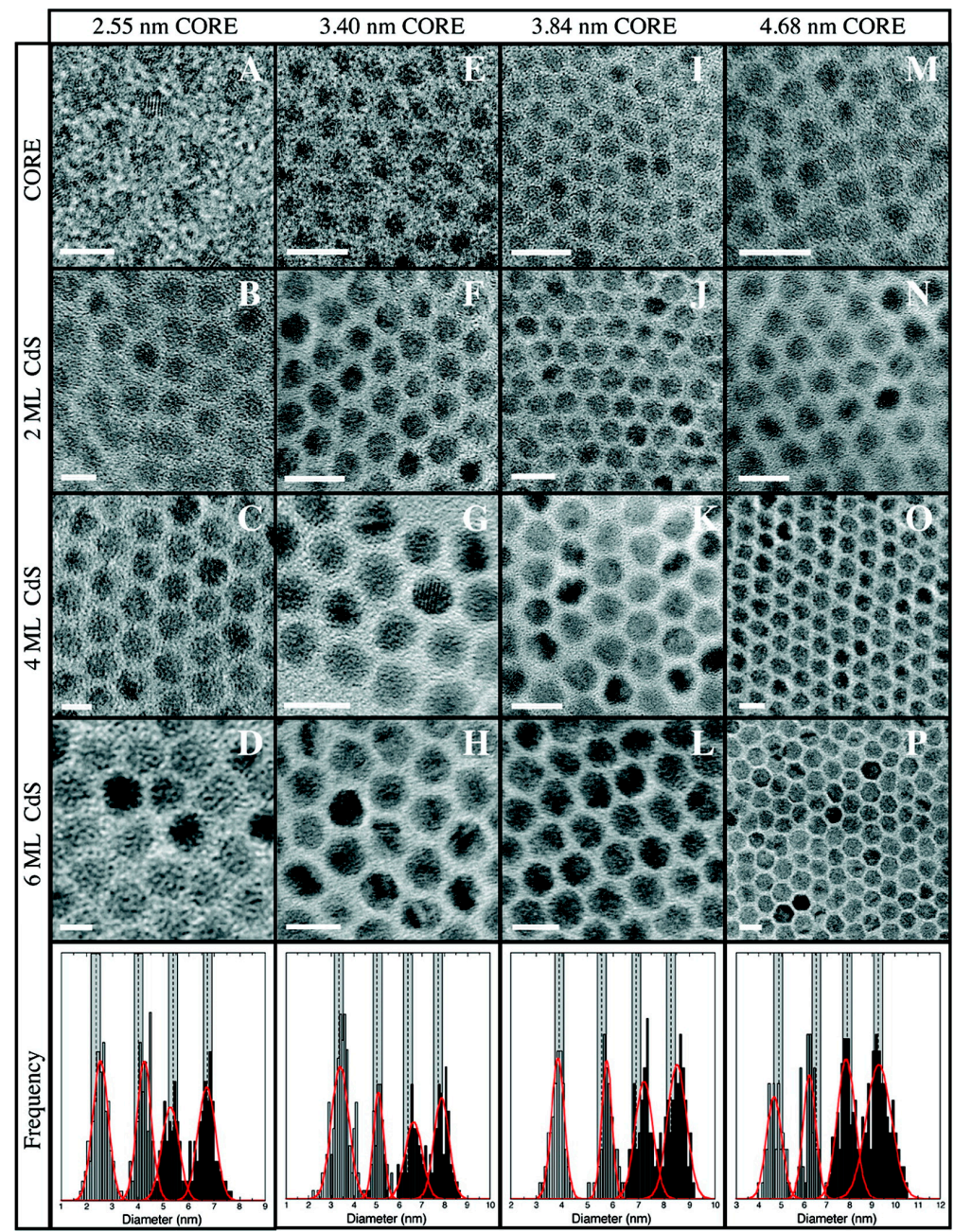

Figure 2. High-resolution transmission electron micrographs of CdSe cores of varying size overcoated by 2, 4 and 6 MLs of CdS. Scale bar equals $5 \mathrm{~nm}$ for Panels A-D and $10 \mathrm{~nm}$ for Panels E-P. Histograms of the measured particle sizes are included for reference, with the dashed lines indicating the predicted size based on the quantity of monomer added. Reprinted with permission from reference [50]. Copyright 2009 American Chemical Society. 
Since SILAR procedures are generally time-consuming and complex, other one-pot methods have been developed. Microwave-assisted syntheses of CdSe/CdS/CdZnS core-shell-shell QDs with high luminescence and excellent stability in aqueous solutions [55] and of Cd based nanocrystals [56] have been tested. This method presents some advantages with respect to injection-based syntheses, such as the selective activation of the target precursor, the high reproducibility from batch to batch, the near-continuous nanocrystal production. Another one-pot synthesis for the epitaxial growth of a graded CdS/ZnS shell onto CdSe core has been reported, giving QDs with superior QY (above 90\%) due to the strong and controlled alloying between two shells which was promoted by the treatment at $310{ }^{\circ} \mathrm{C}$ (see Figure 3) [57].

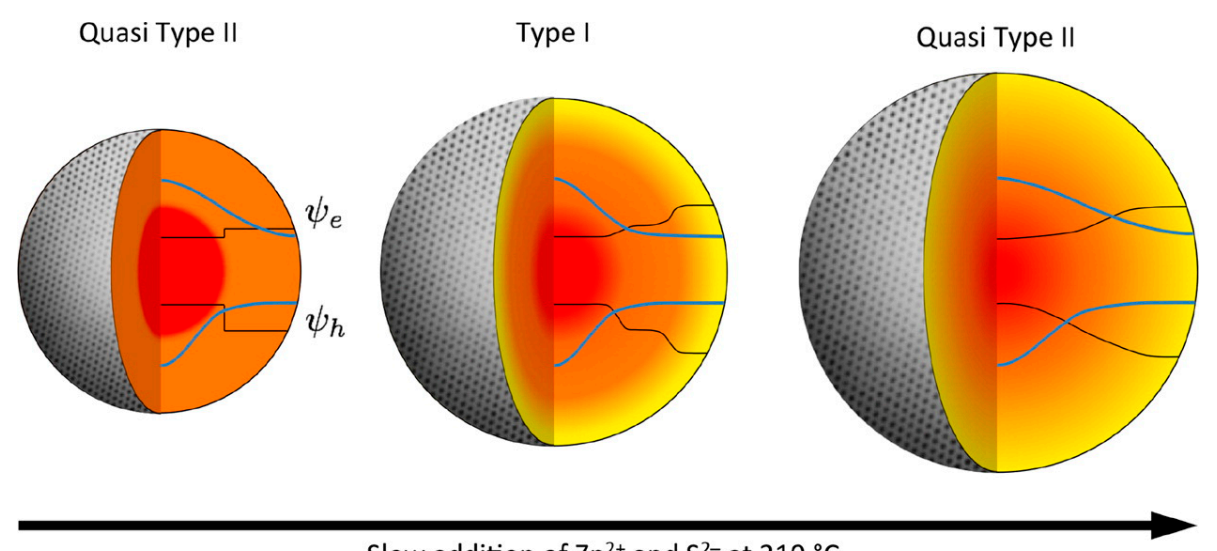

Slow addition of $\mathrm{Zn}^{2+}$ and $\mathrm{S}^{2-}$ at $310{ }^{\circ} \mathrm{C}$

Figure 3. Electronic structure of core/shell/shell QD during ZnS shell growth and alloying. The shell initially confines both e and $\mathrm{h}$ to the core (center), until extended alloying smoothes out the potential well and the electron wavefunction spreads out over the whole structure in a quasi Type-II configuration (right). Reprinted with permission from reference [57]. Copyright 2013 American Chemical Society.

During the last decade, also microfluidics platforms have been improved for the large-scale production of nanocrystals with good control on physical and chemical properties. This improvement has been made possible thanks to the increased inertness of reactors, the integration of sensors for the real-time analysis during each process step and the optimization of algorithms to increase the volume production [58,59]. Nanocrystalline colloids of wide range of materials have been synthetized in microreactors, such as CdTe, CdSe [60], InP [61], or even CdSe/ZnS and ZnSe/ZnS core/shell structures [62]. Albeit the microfluidic approach could in future substitute the batch syntheses, additional improvements are required for the synthesis of particles with more complex compositions and shapes and with controlled photophysical properties.

Recently, a thermal cycling with single-source precursors method has been optimized for the growth of CdSe/CdS core-shell QDs protected with thiol ligands, by means of a ligand exchange process with alkanethiol at room temperature. The obtained nanocrystals possess high crystallinity and QY, thanks to the surface defects passivation with thiols [63].

\subsection{Structural Characterization of Core-Shell Nanocrystals}

At the heart of core/shell QDs is the interface that forms between the core and the shell during growth: the features characterizing the interface region strongly define the final optical properties of the quantum dot [64]. Standard Raman spectroscopy and its surface-enhanced (SERS) analogue have emerged as powerful experimental techniques to probe such interfaces, because they provide direct signatures of the bulk and surface Raman modes from the various materials within a core/shell heterostructure [65]. By comparing the evolution of such bulk and surface modes, SERS has clearly identified that for CdSe-based core/shell structures interfacial alloying is present for CdS shells up to a thickness of $1 \mathrm{~nm}$ (i.e., $\sim 3 \mathrm{ML}$ ), while it is limited to only $0.3 \mathrm{~nm}$ (i.e., $\sim 1 \mathrm{ML}$ ) for $\mathrm{Cd}_{0.5} \mathrm{Zn}_{0.5} \mathrm{~S}[66,67]$. 
This finding is consistent with the reduced lattice strain expected between CdSe and CdS $(\sim 4 \%)$ compared to $\mathrm{Cd}_{0.5} \mathrm{Zn}_{0.5} \mathrm{~S}$ ( $8 \%$ ). Dabbousi's early work on CdSe/ZnS, which has a large lattice mismatch of $\sim 12 \%$, clearly showed that the core/shell interfacial integrity is maintained only up to 1-2 MLs, before lattice strain drives defect formation [47]. In comparison, the presence of the CdSe $\mathrm{S}_{1-\mathrm{x}}$ interfacial alloy in CdSe/CdS distributes the interfacial stresses, thus providing the opportunity to grow large shells without inducing additional interfacial stress [52]. Importantly, this enables such materials to exhibit more homogeneous shape and size distributions compared to their lattice strained counterparts, as well as, facilitates for high quality core/shell materials to be grown with more complex graded structures, e.g., $\mathrm{CdSe} / \mathrm{CdS} / \mathrm{Cd}_{0.5} \mathrm{Zn}_{0.5} \mathrm{~S} / \mathrm{ZnS}$. The formation of an alloy layer at the interface between the core and shell materials has been also confirmed for ZnTe/ZnSe dots using the X-ray photoemission spectroscopy (XPS) technique [68]. The comparison between the effective core diameters from TEM and XPS analyses suggested the formation of an alloyed region of around $0.45 \mathrm{~nm}$ (i.e., below $2 \mathrm{ML}$ ) due to interdiffusion of Te and Se atoms during the dot overgrowth.

One of the most interesting core/shell structures grown through SILAR are the "giant" CdSe/CdS QDs, because they possess a shell thickness of up to 20 CdS MLs (with size as large as about $15 \mathrm{~nm}$ or more) [44]. The large CdS shell ensures that in this system trapping of electrons (or holes) at the external surface is strongly reduced due to its large distance from the core. Additionally, the spontaneous formation of a CdSe $\mathrm{S}_{1-\mathrm{x}}$ alloy [69] at the core/shell interface has a twofold beneficial effect: (i) it reduces the tendency to form defect traps due to lattice mismatch and (ii) it smooths the potential barrier experienced by the carriers thus making non-radiative exciton decay less detrimental (vide infra).

Despite these factors, the main drawback of "giant" CdSe/CdS structures for solution-processable photonic devices are associated with their high volumes, which inherently limit colloidal stability as well as their final density when deposited into a film. Moreover, it has been shown by Javaux et al. [70] that, when operating at room temperature (RT), CdS provides a limited barrier for electron migration towards surface traps even in giant QDs. This stems from the fact that the energy difference between CdSe and CdS CBs approaches $0 \mathrm{eV}$ at RT, which allows charge delocalization and increases trapping at the surface.

Following Javaux's considerations, in order to keep the QD dimensions small, while maintaining high optical properties, the QD structure should provide a smoothed confinement potential that gradually enhances the electronic barrier to prevent carrier migration towards the external surface. The easiest way to obtain such a configuration is to grow a QD with a graded shell composition that possesses a radial increase of the potential barrier from the core to the outer shell. $\mathrm{CdSe} / \mathrm{CdS} / \mathrm{Cd}_{0.5} \mathrm{Zn}_{0.5} \mathrm{~S} / \mathrm{ZnS}$ QDs are an example of a system that is not only synthetically readily accessible using SILAR [70], but overcomes all of the inherent disadvantages presented in pure CdSe/CdS QDs: (i) the inherent alloying between CdSe and CdS minimizes interfacial defect and smooths the confinement potential [67]; (ii) the sequentially higher band gaps provided by $\mathrm{Cd}_{0.5} \mathrm{Zn}_{0.5} \mathrm{~S}$ and $\mathrm{ZnS}$ overlayers provide a gradually confining electronic barrier for both electrons and holes; (iii) the ZnS layer aids to provide enhanced photo-oxidation resistance; and, above all; (iv) all these requirements can be readily achieved within a compact hetero-structure containing less than $6 \mathrm{ML}$ of shelling material (Figure 4). 


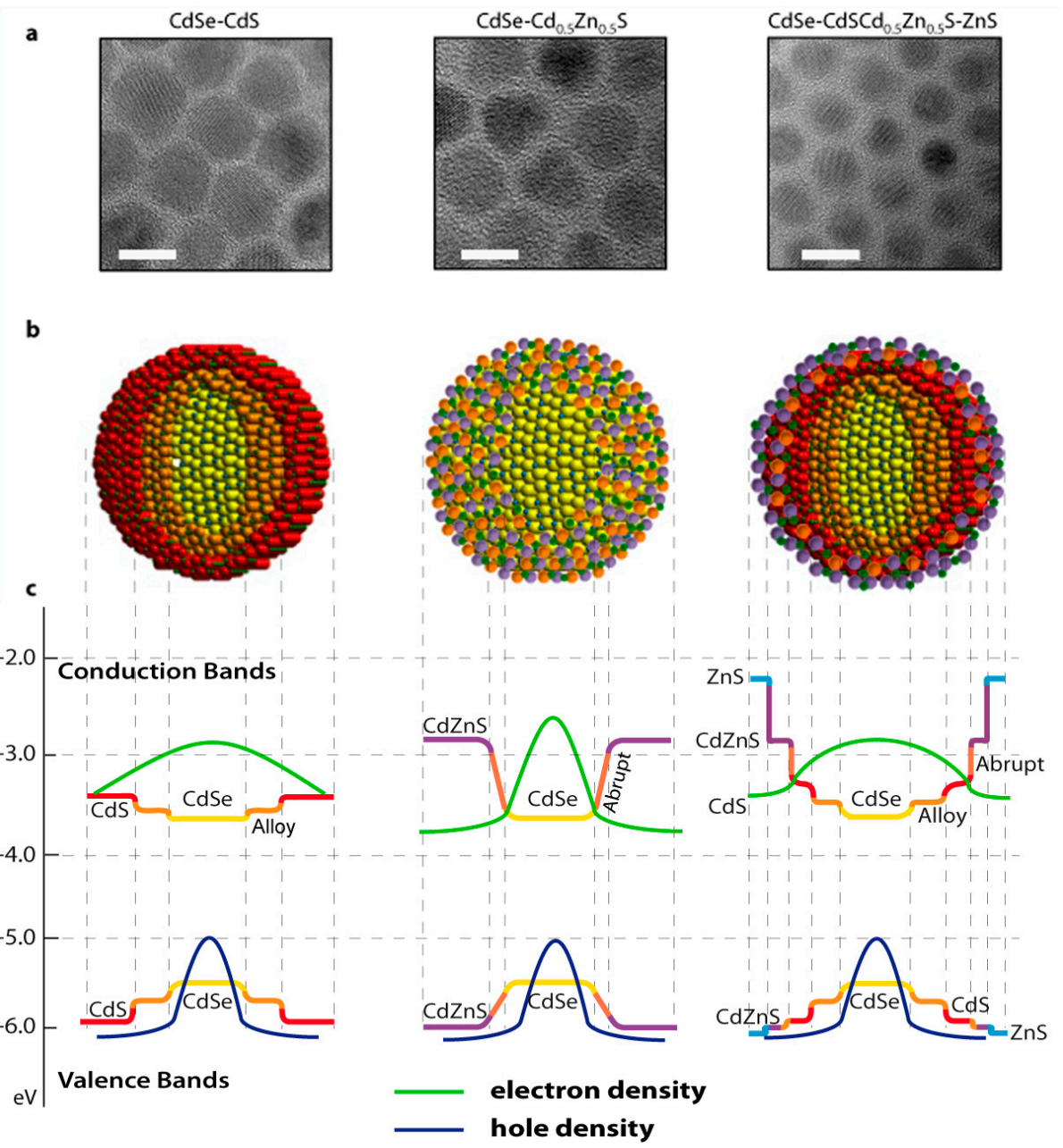

Figure 4. High-resolution transmission electron micrographs (a), cross-sectional core-shell structure depiction (b) and a schematic representation of the electronic (hole) density distribution (c) of CdSe-CdS, CdSe-Cd ${ }_{0.5} \mathrm{Zn}_{0.5} \mathrm{~S}$ and CdSe-CdS-Cd $\mathrm{C}_{0.5} \mathrm{Zn}_{0.5} \mathrm{~S}-\mathrm{ZnS}$ QDs. The scale bar in (a) represents a $10 \mathrm{~nm}$ length. The vertical scale bar in (c) is relative to vacuum and the represented energy levels are that of the bulk materials. (b) is reprinted with permission from reference [66]. Copyright 2013 American Chemical Society.

\section{Fighting Auger Recombination}

In order to harness the favorable luminescence and optical gain properties of QDs, including those of core/shell structures, two major non-radiative recombination pathways inherent in such systems must first be minimized: trapping of carriers at defects and Auger recombination of excitons [71].

$\mathrm{AR}$ is a three-particle phenomenon and occurs when an exciton recombines in a non-radiative way by transferring its energy to a nearby electron (hole) [11]. The electron (hole) is either promoted to a higher level (Figure 5a, with reference to hole excitation) or ionized into the band continuum (Figure $5 b$ ). In QDs such a process is more probable either in the presence of: (i) more than one exciton per dot (Figure 5, right schemes) or; (ii) one exciton in a QD containing an excess charge, i.e., a so-called trion (Figure 5, left schemes). Long-lived excess charges responsible for Auger non-radiative recombination are mostly localized on the QD surface [71,72].

In the literature two main strategies have been pursued to increase the light emission properties of QDs: (i) localization of excitons away from the outer surface (where traps are mainly localized) and (ii) smoothing of the confinement potential, that allows reduction by three orders of magnitude for the Auger recombination rate [73]. 
Direct control of Coulomb interactions between electrons and holes within QDs and with charged traps, respectively, is the main way to manage AR. This can be accomplished through wavefunction engineering using structurally controlled core/shell heterostructures. In the case of emission from single excitons a high degree of overlap between $e$ and $h$ wavefunctions should be maintained. A direct outcome of this strong overlap is an enhanced Coulomb interaction between the carriers that favors fast radiative decay and high QY. Increasing the volume of a core-only nanocrystal reduces this inter-carrier Coulomb interaction and makes trapping at surface defects the most dominant non-radiative process. In this case, it is the Coulomb interaction with charged defects that reduces the luminescence QY by way of non-radiative AR. For the case of multiply excited QDs, a condition that is required to observe optical gain in such systems (vide infra), it is the Coulomb interaction between charge carriers of multiple excitons that triggers the AR.

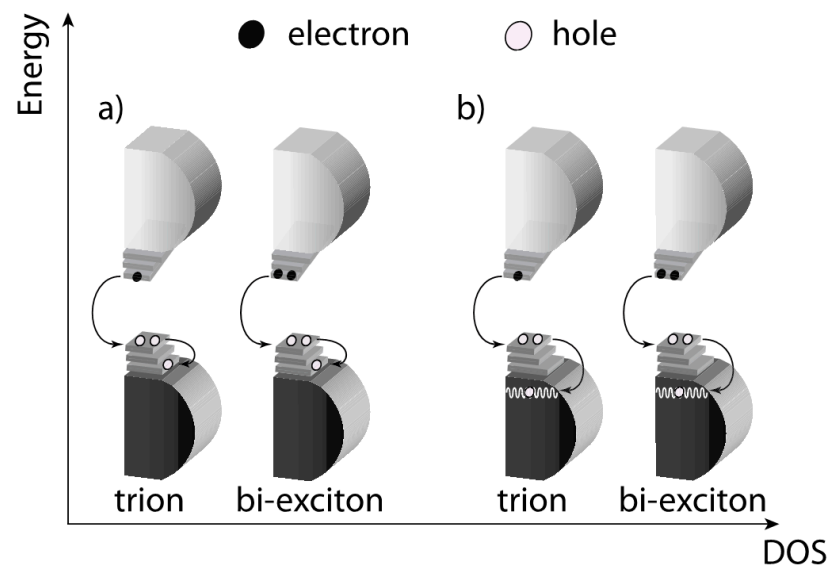

Figure 5. Schematic diagram of non-radiative AR in a QD that acquires a positive charge: in both trion and biexciton case the exciton energy can ejected the extra hole towards discrete levels (a) or into the continuum (b).

In addition to the strategies to reduce Auger non-radiative recombination, much effort has also been spent on optimizing the surface properties of QDs and reducing the local density of charged defects through organic ligand selection $[6,14,15,46]$ or through the growth of epitaxial Type-I core/shell structures [4,31]. Organic molecules, sometimes also used for the QD solubilization, have to be accurately selected, since some organic groups can act as additional surface trap state, causing a reduction of the nanocrystal QY. The growth of a wider bandgap inorganic shell on the inner core overcomes this problem, resulting in a significant improvement of the photoluminescence efficiency, while simultaneously reducing the photodegradation and increasing the shelf life. However, in a core/shell QD the high photoluminescence QY is a trade-off between protecting against trapping at the surface defects and causing the introduction of additional traps at the core-shell interface, often influenced by the lattice mismatch between different materials [74]. The control of defects is still challenging and a QD ensemble, used in most practical applications, is inherently poly-dispersed because of dot-to-dot variability in size, surface and core-shell interface properties. It is indeed demonstrated that the shell coverage is sometimes inhomogeneous (i.e., with incomplete, "pinched" or "divot" shapes) and inefficient from dot to dot [75].

A successful route to high QY QDs, based on the simple and effective idea of using large shells, was independently demonstrated in 2008 by Klimov [52] and by Dubertret [76]. These so-called "giant" $Q D s$ consist of a core embedded within a thick shell that effectively confines the carriers in the core (Type-I structure) and hinders their tunneling or diffusion towards the surface [69,73]. In addition, in CdSe/CdS QDs the reduction of non-radiative AR benefits from the formation of a CdSe $\mathrm{S}_{1-x}$ alloy layer at the core-shell interface. Such layer has the effect of smoothing the interface potential barrier. In a nutshell, the rate of AR is large if the wavefunction overlap between the initial carriers and the 
final hot carrier is also large. For the carriers of the exciton, this may occur close to the core/shell interfaces if the associated confinement potential is abrupt. Smoothing of this potential acts to reduce this degree of overlap, thereby providing a facile approach to reducing the AR rate by up to one order of magnitude. Exploiting a similar concept, nanocrystals having quasi Type-II or Type-II electronic structure have been studied. Research on colloidal Type-II systems was triggered by the seminal work of Bawendi et al., describing the synthesis and optical properties of CdTe/CdSe and CdSe/ZnTe nanocrystals [77]. Type-II QDs are characterized by a partial or complete separation of the electron and the hole wavefunctions. When multiple excitons are created in the QD, the spatial separation of $e$ and $h$ wavefunctions induces a repulsive exciton-exciton Coulomb interaction, which promotes the reduction of Auger recombination [34,78,79].

Since the AR time is generally described by a volume scaling dependence, a reduction of Auger recombination has been found for elongated shape nanocrystals, such as nanorods [80], nanobundles [81] and nanoplatelets [37]. In addition, also for spherical dots, theoretical calculations on Auger recombination rates in highly confined structures showed that there are some "magic sizes" that promote the almost complete Auger suppression, due to the destructive interference between the initial and final states. Since such AR rates minima have very narrow widths (1-2 Å), random temperature and electric fields fluctuations and size distribution strongly limit the detection of these "magically sized" dots, at least at room temperature [73]. In the future, the development of synthetic procedures for the precise control on the dot size could allow the production of nanostructures with enhanced optical properties in terms of emission yield and optical gain efficiency.

\section{Influence of Shell Composition on QDs Optical Properties}

An alternative approach to giant core-shell QDs is to surround the core with a multilayer shell with a varying composition of each monolayer. To clarify why graded core-shell CdSe-CdS-Cd ${ }_{0.5} \mathrm{Zn}_{0.5} \mathrm{~S}-\mathrm{ZnS}_{\mathrm{n}}$ are highly performing QDs for optical applications [70,82], the correlation of CdSe-Cd $\mathrm{Zn}_{1-\mathrm{x}} \mathrm{S}$ QDs emitting properties as a function of shell thickness, structure and composition was recently investigated by our group [83]. Typical CdSe-CdS, absorption (and emission) spectra, with increasing number of shell MLs, are reported in Figure 6a,b. The red-shift of the first excitonic peak (and of the emission peak) that is observed with shell growth is due to the aforementioned delocalization of electrons into the surrounding shell [51,67]. This behavior is observed in all CdSe-Cdx $\mathrm{Zn}_{1-\mathrm{x}} \mathrm{S}$ QDs, but it is naturally less pronounced in "Zn-rich" materials, i.e., $\mathrm{Cd}_{0.5} \mathrm{Zn}_{0.5} \mathrm{~S}$ and $\mathrm{ZnS}$ shell, due to their larger confinement potentials [83].

The QY also exhibits a strong dependence on shell thickness and composition (Figure 6c). Notice that the direct growth of a ZnS shell onto the CdSe cores does not provide any improvement in QY. The lattice mismatch is too large as the synthesis temperature is too low to permit ion interdiffusion [84] and strain is released by defect formation [47,51]. For the intermediate CdSe-Cd $\mathrm{C}_{0.5} \mathrm{Zn}_{0.5} \mathrm{~S}$ series, the QY increases from $10 \%$ to $45 \%$ after the first shell ML deposition and then saturates. Such an abrupt increase is justified with the higher confining potential of $\mathrm{Cd}_{0.5} \mathrm{Zn}_{0.5} \mathrm{~S}$.

In order to understand the influence of core/shell interfaces and shell thickness on exciton recombination dynamics, time-resolved emission experiments from each $\mathrm{CdSe}-\mathrm{Cd}_{\mathrm{x}} \mathrm{Zn}_{1-\mathrm{x}} \mathrm{S}$ series were performed. Charge trapping and de-trapping at core/shell and external QD surfaces occurs on the same time scale as exciton recombination. As such, CdSe-Cd $\mathrm{Zn}_{1-\mathrm{x}} \mathrm{S}$ QDs exhibit convoluted multiexponential emission decay behavior that can only be interpreted according to a recently derived kinetic model by Jones et al. [85]. This kinetic model considers the physically realistic QD structure and the associated radial traps states, which unequivocally enables the extraction of the radiative $\left(k_{R}\right)$ and non-radiative $\left(k_{N R}\right)$ decay and the trapping/de-trapping rates for different core/shell QDs.

From the results of our systematic analysis, it is evident why graded QDs are high performing materials for light emission applications [70]: (i) they retain in a single entity the high radiative decay rates of CdS; (ii) they exhibit high de-trapping and low non-radiative decay rates of $\mathrm{Cd}_{0.5} \mathrm{Zn}_{0.5} \mathrm{~S}$; and (iii) they possess the superior confinement potential of $\mathrm{ZnS}$. 

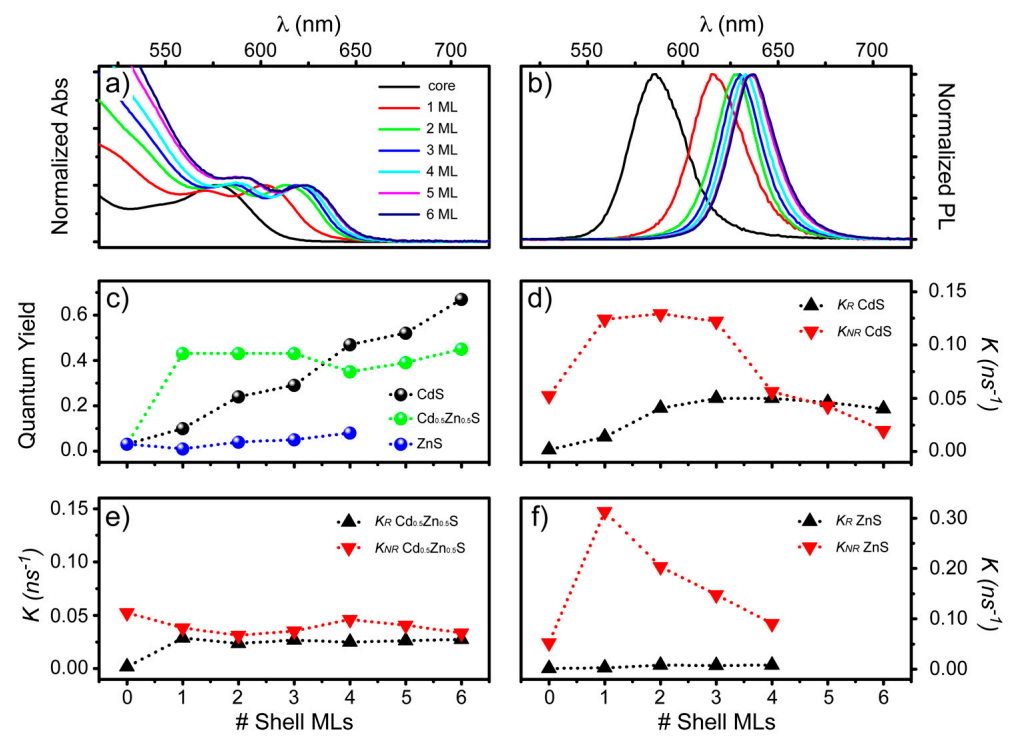

Figure 6. Absorption (a) and emission (b) spectra of CdSe-CdS QDs as a function of shell ML number; (c) QY of core-shell QDs based on CdSe core and different shell as a function of shell ML number; (d-f) Radiative $\left(k_{R}\right)$ and non-radiative $\left(k_{N R}\right)$ recombination rate of CdSe based core/shell as a function of shell type and ML number.

\section{Use of QDs for Light Emission Applications}

In the previous sections, we focused the attention on the nanoscale properties of semiconductor QDs in terms of surface chemistry, interface features at the core-shell region, size and shape properties. All these characteristics can affect their electronic and optical properties. In the following chapter, we will summarize the foremost results of two applications of QDs as light emitters: the optical gain and the displays applications.

\subsection{Optical Gain and Lasing Applications}

Colloidal nanocrystals have been extensively studied as prospective materials for the realization of solution-processed lasing media with broadly tunable emission wavelengths. Optical gain, defined in terms of the difference between the stimulated emission and absorption rates, is the main property to be boosted to reach high performances for lasing applications.

Both theoretical and experimental data have clearly demonstrated that optical-gain performances improve from the suppression of Auger recombination [83,86,87]. Population inversion in nanocrystal takes place when the average number of excitons per nanocrystal is greater than 1 , this means that the optical amplification is due to multiexcitonic excitation [88]. The Amplified Spontaneous Emission (ASE) originates from the relaxation between the biexcitonic and the single exciton states. Fast relaxation of optical gain resulting from Auger non-radiative decay represents a major complication for both generating population inversion and maintaining it for time durations sufficient for the development of the lasing regime; longer optical gain lifetimes support inversion buildup, responsible for lasing action, and yield lower lasing thresholds. It has been also demonstrated that it is possible to obtain optical gain also in the single-exciton regime using Type-II core/shell CdS/ZnSe hetero-nanocrystals [87]. The resulting imbalance between negative and positive charges following a charge separation process produces a strong local electric field and a transient Stark shift of the absorption spectrum. This eliminates absorption losses at the nanocrystal emission wavelength, allowing optical gain using single-exciton states.

Giant QDs [89], consisting of a small CdSe core overcoated with a thick shell of up to 19 CdS monolayers, and CdSe/ZnS core/shell colloidal quantum rods, with 1.5-2 ZnS shell layers, present 
a significant suppression of Auger recombination. The lowest ASE threshold $\left(6 \mu \mathrm{J} / \mathrm{cm}^{2}\right)$ and the highest gain coefficient $\left(521 \mathrm{~cm}^{-1}\right)$ have been measured for CdSe colloidal Quantum wells under fs pumping, thanks to their large oscillator strength and consequently large spontaneous and stimulated cross sections. Importantly, these features have also allowed the activation of stimulated emission under CW excitation at $444 \mathrm{~nm}$ with a threshold of $6.5 \mathrm{~W} / \mathrm{cm}^{2}$ [90]. Graded QDs and nanorods [91] possess slightly reduced ASE characteristics, but are none-the-less more than sufficient to achieve lasing within different prototype structures (see Table 1).

To fabricate lasers, NCs are incorporated within an appropriate micro-cavity to provide optical feedback [25,92-96] or dispersed in solution in an open access microcavity [97]. Devices without cavity have also been investigated based on the random laser action [98] and pioneering experiments have shown that also a single QD emitter can drive a nanocavity system into stimulated emission $[99,100]$. Lasing devices, with high quality performances, have been experimentally tested by using different micro-cavities, like micro-ring [25], spherical resonators [92], distributed Bragg reflectors (DBR) [93,97], and distributed feedback (DFB) [94]. Some laser prototypes have also been demonstrated to operate both under direct one-photon optical pumping and through a two-photon absorption induced up-conversion mechanism, i.e., producing a laser beam with wavelength in the visible range upon IR excitation $[95,96]$.

Two-photon excitation is achieved through the simultaneous absorption of two photons, which induces an electronic transition from the ground to an excited state via virtual states [101,102]. It possesses several unique features such as higher spatial resolution and longer penetration depth when operating in the semitransparent infrared window of biological media. Additionally, for the generation and wavelength tuning of coherent light, the absence of a phase matching requirement in the two-photon emission process, makes it highly attractive over other nonlinear frequency conversion techniques (e.g., optical harmonic generation), as this permits its application to a much wider range of resonator designs and gain media. Given the advent of robust, low-cost, versatile, and compact IR laser sources (e.g., fiber lasers), two-photon excitation has become a viable technique for the generation of coherent light via the attainment of optical gain and lasing in colloidal semiconductor NCs [103-105]. Moreover, in contrast to UV-vis excitation, optical pumping via two-photon excitation at IR wavelengths has another advantage-it can reduce the adverse photodamage process on photoactive materials.

As previously described, graded core/shell QDs combine favorable optical properties, like high absorption cross-sections and QY, extremely high photostability under laser irradiation, high optical gain efficiency and low ASE thresholds to be employed for developing QD based micro-lasers [82,95]. They are also particularly interesting candidates as active material for miniaturized lasers since their structure can be precisely controlled and their surface chemistry can be readily modified, which allows for their efficient inclusion into solid films. Our group has recently shown that graded QDs hosted in a suitable $\mathrm{ZrO}_{2}$ sol-gel matrix are photo-chemically stable and can be prepared at sufficiently low temperatures to retain the beneficial optical properties of the NCs [103,106]. Sol-gel techniques, in general, enable the preparation of solution processable layers with tailored optical and mechanical properties, such as controlled thickness, suitable refractive index and stiffness [107]. These properties have been harnessed to fabricate a laser device prototype by simply depositing graded QDs embedded within a $\mathrm{ZrO}_{2}$ host on top of a 1D DFB grating, which was obtained through nano-imprinting of a germania-based sol-gel matrix (Figure 7a,b) [95]. The combined effect of active film thickness, refractive index and grating period, entails direct tunability of the laser's output spectra within the gain profile [108]. These features have enabled single mode lasers (Figure $7 \mathrm{c}, \mathrm{d}$ ) to be demonstrated with a low lasing threshold of $77 \mu \mathrm{J} / \mathrm{cm}^{2}$ (Figure $7 \mathrm{c}, \mathrm{d}$ ). Such lasers can operate also in an up-converted configuration at $800 \mathrm{~nm}$ excitation, giving lasing thresholds two orders of magnitude lower than those of organic small molecules [109] and about one order of magnitude smaller than those of QDs micro-bead systems [92] and CdSe/CdS nanoplatelets [93]. 
Table 1. Summary of ASE and Lasing parameters for different classes of NCs.

\begin{tabular}{|c|c|c|c|c|c|c|c|c|}
\hline Sample & $\begin{array}{l}\text { Gain Coefficient } \\
\left(\mathrm{cm}^{-1}\right)\end{array}$ & $\begin{array}{c}\text { 1-Photon ASE } \\
\text { Threshold } \\
\left(\mu \mathrm{J} / \mathrm{cm}^{2}\right)\end{array}$ & $\begin{array}{c}\text { 2-Photon ASE } \\
\text { Threshold } \\
\left(\mathrm{mJ} / \mathrm{cm}^{2}\right)\end{array}$ & Laser Cavity & $\begin{array}{c}\text { Stability } \\
\text { (Laser Shots) }\end{array}$ & $\begin{array}{c}\text { 1-Photon } \\
\text { Lasing Threshold } \\
\left(\mu \mathrm{J} / \mathrm{cm}^{2}\right)\end{array}$ & $\begin{array}{c}\text { 2-Photon } \\
\text { Lasing Threshold } \\
\left(\mathrm{mJ} / \mathrm{cm}^{2}\right)\end{array}$ & Q-Factor \\
\hline $\begin{array}{c}\text { Giant QDs } \\
{[89]}\end{array}$ & & 26 & & - & & & & \\
\hline $\begin{array}{c}\text { Quantum wells } \\
{[89,90]}\end{array}$ & $\begin{array}{c}521 \text { (fs-pump) } \\
121 \text { (CW-pump) }\end{array}$ & 6 & & & & & & \\
\hline $\begin{array}{l}\text { NR } \\
{[91]}\end{array}$ & $\begin{array}{c}350 \\
\text { (until } 120 \mathrm{~K} \text { ) }\end{array}$ & $2.5 \times 10^{5}$ & & & & & & \\
\hline $\begin{array}{c}\text { Graded QDs } \\
{[82]}\end{array}$ & 180 & 170 & 12.8 & DFB & & 77 & 8.3 & 650 \\
\hline $\begin{array}{c}\text { CdSe/CdS NR } \\
{[110]}\end{array}$ & & & 1.5 & Spherical resonator & $\begin{array}{c}6 \times 10^{6} \\
(1 \& 2-\text { ph pumping })\end{array}$ & 12 & 0.99 & 800 \\
\hline $\begin{array}{c}\text { NPLs } 25 \text { nm } \\
\text { core/crown } \\
\text { [93] }\end{array}$ & 650 & 41 & 4.5 & DBR & $10^{4}-10^{5}$ & - & 2.49 & 270 \\
\hline $\begin{array}{c}\text { CdSe/CdSeS/CdS } \\
{[111]}\end{array}$ & 120 & 29 & 5.02 & DBR & $\begin{aligned} 1.8 & \times 10^{7} \\
(\text { pump int. } & \left.=35 \mu \mathrm{J} / \mathrm{cm}^{2}\right)\end{aligned}$ & NO Lasing & 0.764 & - \\
\hline
\end{tabular}


a)
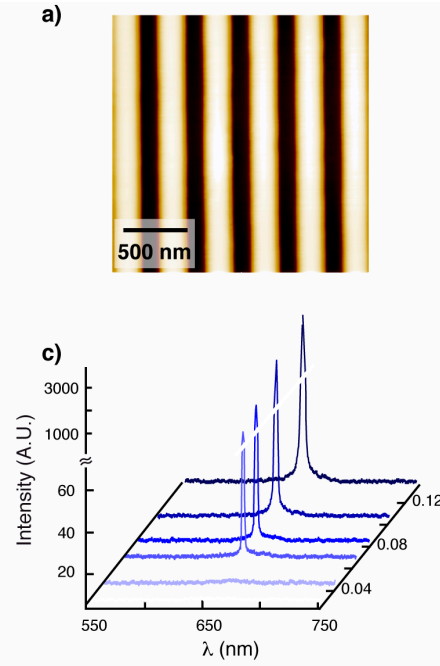

Laser pulses

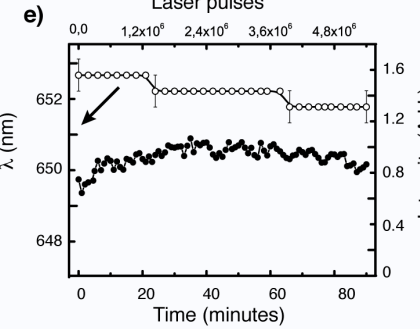

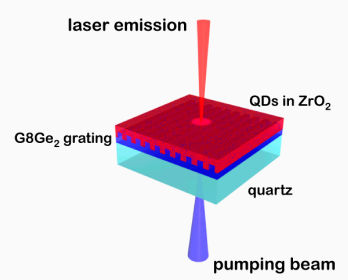

b)

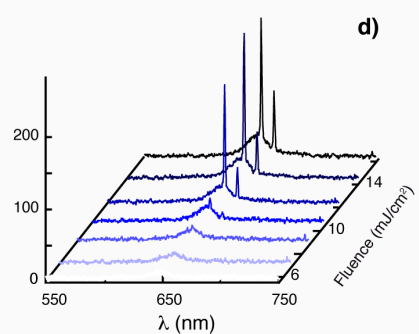

d)

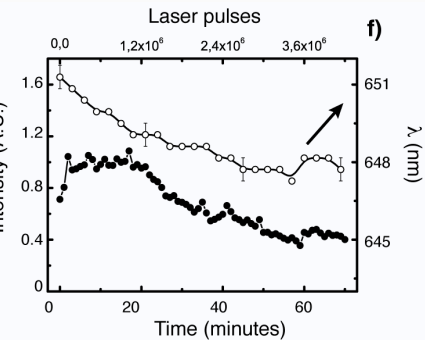

Figure 7. DFB grating (a) and scheme of the laser prototype (b). Laser emission measurements, carried out by one- (c) and two-photon (d) optical pumping, show lasing emission above the optical gain threshold: TM (with electric field polarized perpendicular to the grating grooves) and TE (with polarization in the plane of incidence parallel to the grating grooves) lasing modes are detected. The threshold fluences are $0.077 \pm 0.023$ and $0.108 \pm 0.056 \mathrm{~mJ} / \mathrm{cm}^{2}$ for the one-photon pumped TM and TE modes respectively, and $8.3 \pm 2.5$ and $11.4 \pm 3.2 \mathrm{~mJ} / \mathrm{cm}^{2}$ for the up-converted ones. Photostability of TM mode at one- (e) and two-photon pumping (f). Reprinted with permission from reference [95]. Copyright 2011 The Royal Society of Chemistry.

Lasing under one- and two-photon pumping has been obtained also using seeded CdSe/CdS nanorod (NR) heterostructures, comprising as the optical gain media a spherical CdSe core of $2.4 \mathrm{~nm}$ diameter, encapsulated by a rod-like CdS shell of $39 \mathrm{~nm}$ [110]. While the CdS shell functions as an antenna in light harvesting, emission from the rod originates primarily from the CdSe core. One of the main advantages of this optical configuration is the realization of a material with variable emission wavelength: emission can be tuned by adjusting the physical dimensions of the rod-like shell and the spherical core. For $39 \mathrm{~nm}$ long NRs, a two-photon absorption cross-section value of $2.3 \times 10^{5} \mathrm{GM}$ (where $1 \mathrm{GM}=10^{-50} \mathrm{~cm}^{4} \cdot \mathrm{s} /$ photon) was measured [110], which is 2 to 4 orders of magnitude larger than that previously reported for spherical semiconductor QDs and about 4 orders of magnitude larger than that of typical organic dyes [102]. Importantly, two-photon absorption cross-section can be varied independently of the CdSe core dimension, whose size primarily determines the emission wavelength. The advantages of size-dependent emission afforded by the quantum- confined CdSe core are therefore preserved in these heterostructures. Figure 8a shows an optical image of a typical NR-coated microsphere under optical excitation [110]. These nanostructures have been characterized by room temperature ASE, via two-photon excitation at $800 \mathrm{~nm}$, showing extremely low thresholds $\left(1.5 \mathrm{~mJ} / \mathrm{cm}^{2}\right)$. NRs have also been used as gain medium for two-photon pumped lasing using a spherical optical cavity. To this end, CdSe/CdS NRs were chemically functionalized and incorporated into a sol-gel silica matrix to permit the adhesion of a thin layer of NRs-silica onto the exterior of commercially available silica microspheres (of $5.0 \mu \mathrm{m}$ diameter) and to increase the damage 
resistance of samples to prolonged pulsed excitation. Under two-photon pumping a single-mode lasing was achieved (Figure 8b). It is characterized by a threshold fluence of $990 \mu \mathrm{J} / \mathrm{cm}^{2}$, a laser line with a full-width-at-half-maximum (FWHM) of $0.75 \mathrm{~nm}$, corresponding to a Q-factor of 800 and a photostability for over $6 \times 10^{6}$ laser shots under ambient conditions, evaluated by monitoring the lasing intensity as a function of time under a continuous irradiation at a $1 \mathrm{kHz}$ repetition rate under ambient conditions.
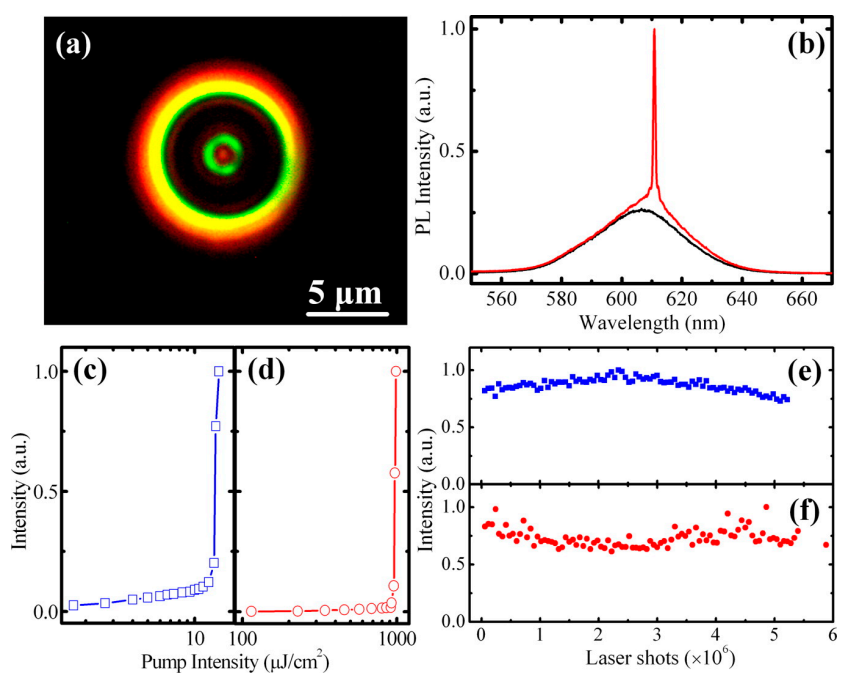

Figure 8. (a) Optical image of a $5 \mu \mathrm{m}$ silica microsphere coated with a CdSe/CdS NR film; (b) Emission spectra of NR coated microsphere below $\left(800 \mu \mathrm{J} / \mathrm{cm}^{2}\right)$ and above $\left(900 \mu \mathrm{J} / \mathrm{cm}^{2}\right)$ lasing threshold under one-photon pumping; (c,d) Emission intensity as a function of pump intensity for one- (blue) and two-photon excitation (red). Photo-stability under one- (e) and two-photon (f) excitation. Reprinted with permission from reference [110]. Copyright 2012 American Chemical Society.

Among Nanoplatelets, CdSe/CdS core/crown NPLs (or also denoted as CdSe/CdS nano-heteroplatelets with CdS wings) are highly attractive due to their photophysical properties [93]. The peak emission wavelength of the core/crown NPLs does not change (except for a few nanometers red shift) as compared to their core-only counterparts owing to the confinement of the excitons in the core. The core/crown NPLs preserve the narrow spontaneous emission properties of the core-only NPLs, while the absorption cross section of the NPL is boosted due to the energy transfer from the crown to the core. Finally, with the growth of CdS crown, the quantum yield and stability of the NPLs are enhanced. Optical performances of a core only sample, constituted by four CdSe monolayers with a final shape varying between square and rectangle and an average long-edge length of $16.8 \mathrm{~nm}$, have been compared to the optical performances of core/crown NPLs, with a CdS crown lateral growth and an average size of $25 \mathrm{~nm}$. The core/crown NPLs demonstrate substantially lowered ASE thresholds as compared to the core-only NPLs: the one- and two-photon pumped ASE thresholds have been determined to be $41 \mu \mathrm{J} / \mathrm{cm}^{2}$ and $4.5 \mathrm{~mJ} / \mathrm{cm}^{2}$, respectively, for the core/crown sample, while $214 \mu \mathrm{J} / \mathrm{cm}^{2}$ and $8.2 \mathrm{~mJ} / \mathrm{cm}^{2}$, respectively, for the core only sample. Besides, the gain coefficient of the core/crown NPLs is measured as high as $650 \mathrm{~cm}^{-1}$.

Lasing with core/crown NPLs has been experimented in a Distributed Bragg Reflectors configuration, made out of alternatively stacked $\mathrm{SiO}_{2}$ and $\mathrm{TiO}_{2}$ nanoparticles. Employing six bilayers of the $\mathrm{SiO}_{2} / \mathrm{TiO}_{2}$, a DBR system with peak reflectively as high as $91.93 \%$ has been obtained. The vertical cavity surface-emitting laser (VCSEL) of the NPLs has been realized by sandwiching $25 \mathrm{~nm}$ size core/crown NPLs between two DBRs (Figure 9). The figure shows the emission spectra of VCSELs under two-photon pumping as the pump intensity is progressively increased: above the lasing threshold $\left(2.49 \mathrm{~mJ} / \mathrm{cm}^{2}\right)$ peak at $535 \mathrm{~nm}$ emerges with a FWHM of $2 \mathrm{~nm}$, corresponding to a Q-factor of 270 [93]. 
(a)

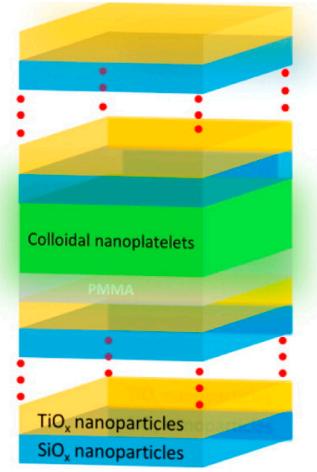

(b)

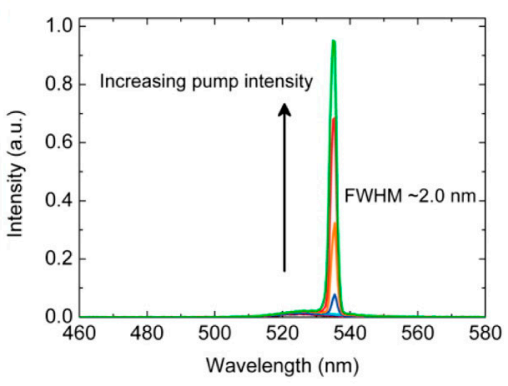

(c)

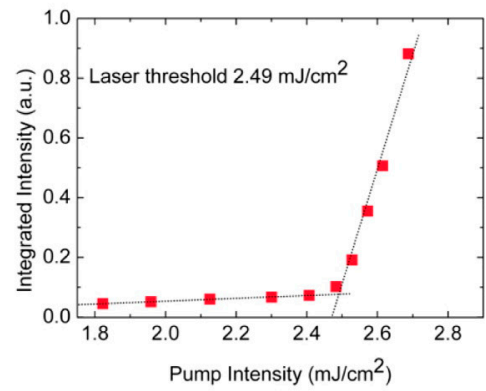

Figure 9. (a) Scheme of the VCSEL of the NPLs employ DBR with a six bilayer stack of $\mathrm{SiO}_{2}$ and $\mathrm{TiO}_{2}$ nanoparticles each; (b) Emission spectrum of VCSEL at increasing pumping intensity; (c) Integrated emission intensity vs. 2-photon pump intensity. Reprinted with permission from reference [93]. Copyright 2014 American Chemical Society.

Recently, very high performance and extremely stable optical gain media, via both one- and two-photon pumping, have been obtained using tailored CdSe-core/CdS-shell QDs [111]. High-quality zinc-blende (ZB) CdSe nanocrystals have been grown followed by slow CdS-shell growth at high temperature to improve the crystal quality. By growing the CdS shell at an exceptionally high temperature $\left(310^{\circ} \mathrm{C}\right)$ and at a very slow rate $(6$ monolayers in $3 \mathrm{~h})$, a smooth $\mathrm{Cd}(\mathrm{Se}, \mathrm{S})$ interface layer with a thickness of 2-4 monolayers is likely to have been created. This relatively thin CdS shell helps to combine the small nanocrystal size, high photoluminescence quantum yield and the high performance optical gain - a low threshold of $29 \mu \mathrm{J} / \mathrm{cm}^{2}$ and extremely high stability $\left(1.8 \times 10^{7}\right.$ laser shots under one-photon pumping). The high-performance QD gain medium is further demonstrated in an all-colloidal vertical-cavity surface-emitting laser (AC-VCSEL) using simple and solution-processed DBR of just 96\% reflectivity. With the solution-processed DBRs and the tailored core/shell QDs, an ultralow frequency up-converted lasing threshold of $764 \mu \mathrm{J} \cdot \mathrm{cm}^{-2}$ have been achieved (Figure 10) [111].

(a)

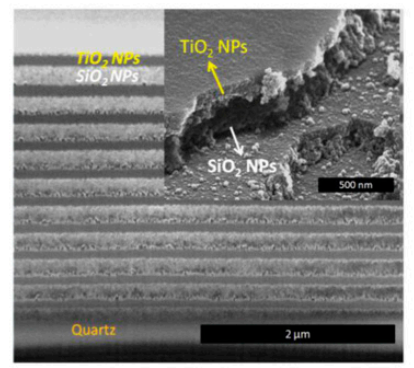

(c)

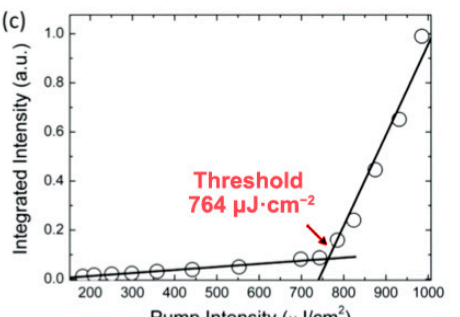

Pump Intensity $\left(\mu \mathrm{J} / \mathrm{cm}^{2}\right)$ (b)

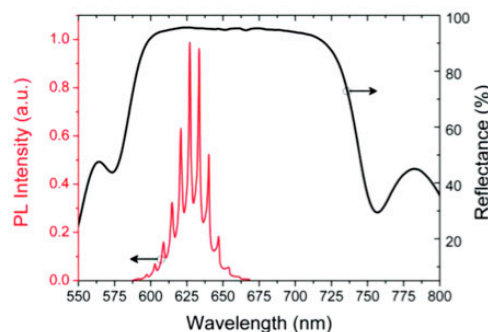

(d)

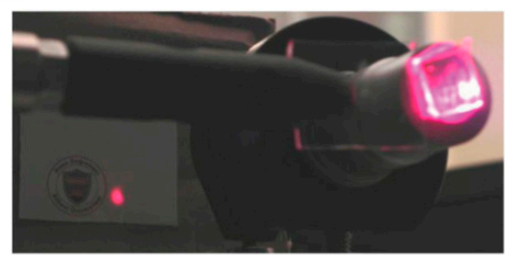

Figure 10. (a) Scanning electron microscopy cross-sectional image of DBR structure; (b) Surface normal reflectance of DBR with ten-bilayer of $\mathrm{TiO}_{2}$ and $\mathrm{SiO}_{2}$ nanoparticles along with the emission of the QDs in the cavity with $15 \mu \mathrm{m}$ optical thickness; (c) Emission intensity vs. pump intensity for frequency up-converted VCSEL; (d) Photographic image of the lasing spot from the VCSEL. Reprinted with permission from reference [111]. Copyright 2015 Wiley. 
The use of such engineered nanocrystals (graded QDs, NRs or NPLs), possessing lower oneand two-photon pumped lasing thresholds than the spherical semiconductor QDs, allows the implementation of all-solution-processed QD-laser technologies, representing the leading most cost-effective approach towards high-performance full-color lasers with single material technology.

\subsection{Display Applications}

The efficiency and color quality of a liquid crystal display (LCD) is mainly dictated by the quality of the white backlight module and the optimal monochromaticity of filters used for the selection of single Red-Green-Blue subpixel components. To this end, large efforts have been devoted to the generation of new strategies to meet the full color gamut accordingly to the National Television Systems Committee (NTSC) standard requirements (CIE 1931 [112] or CIE 1976 [113]). In addition to such fundamental color and brightness requirements, other features are important for the optimal performing display, such as the fast response time, wide viewing angle, black background (in particular in a dark place), low energy consumption and costs, flexibility and compactness. Up to few years ago, the organic light emitting diode (OLED) technology has shown the best performances in terms of luminosity, wide gamut range, response time, true black light and compactness. However, the high production costs and commercial scaling issues limit the widespread use of OLED to smaller devices [114].

Recently, inorganic QDs are emerging as one of the most promising emitting materials for next generation LCDs. Thanks to their intrinsic optical properties, such as their broad absorption band, narrow emission spectra, high fluorescence quantum yield, high photostability and controllable emission and surface properties, QDs based LED is now showing performances comparable or even better than OLED devices [2,3,115]. For display applications, QDs can be used either exploiting their photoluminescence for LCD backlight unit $[116,117]$ or their electroluminescence for QDs-light emitting diodes (QLED) [118,119].

One of the technologies to employ QDs as down-conversion emitters involves the encapsulation of green and red QDs in a tube or "rail", placed directly in front of blue LEDs on the edge of the panel (see Figure 11). By combining the blue optical excitation with the QDs emission in the red and green regions, all three R-G-B primaries are produced. From a technological point of view, there are two different packaging strategies for the preparation of QLED, named respectively remote-type and on-chip type. The main difference is that in the first case the QDs are included into a flat polymeric slab, which is further used to cover the Blue-LED chip, while in the second type the QDs-polymeric mixture is solidified directly on top of the LED chip. In both cases, the QD-LED assembly needs a further encapsulation for the protection towards oxygen, moisture and temperature. One of the most used hosting polymers is PMMA [120,121]. The final structure of the protective coating can also influence the overall light output efficiency. Throughout all the processing steps, there are many critical aspects that need to be further optimized in order to increase the light emission performances. They include: the surface chemistry properties at the interface between the QDs and polymeric matrix to avoid agglomeration and reduction of QD emission efficiency [122,123], the right mixture of different QDs components to achieve high-color rendering ability [124-126] and the encapsulation matrix able to protect the chip and to prolong its lifetime $[127,128]$. For an overview on the main strategies reported in literature, in particular for highly efficient white-light LED, refer to the recent review written by Xie and colleagues [129].

The in-rail approach has already commercially demonstrated within specific Sony displays; however the additional mechanical element added to the LCD configuration does place restrictions on the possibility of converting it into a more light and flexible display [130,131].

Two alternative approaches have been proposed respectively by NanoSys ${ }^{\circledR}$ in collaboration with $3 \mathrm{M}^{\circledR}$ and by QD Vision ${ }^{\circledR}[130,132,133]$. NanoSys proposed a Quantum Dot Enhancement Film (QDEF), a flat film doped with Red and Green QDs placed in front of the backlight blue LED illumination within the LCD architecture (see Figure 12). 
a)

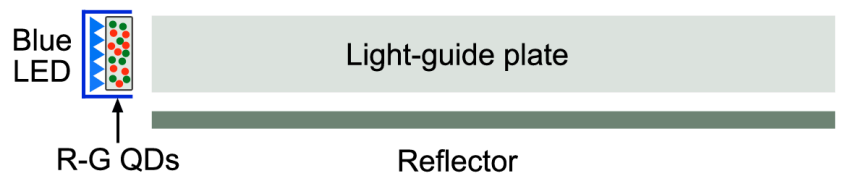

b)

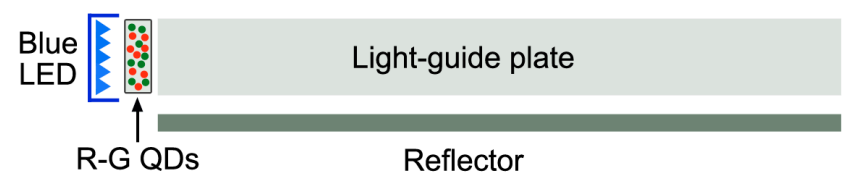

Figure 11. Depiction of the on-edge implementation QLED geometries. QDs are placed within the Blue LED package, which is coupled to the light guide (a) or between the Blue LED package and the light guide plate $(\mathbf{b})$.

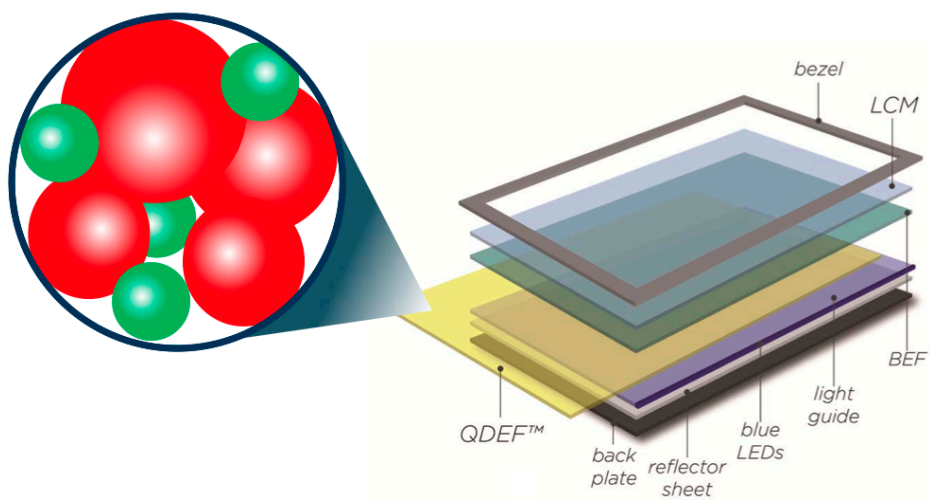

Figure 12. QDEF integration into an LCD backlight. QDEF is sandwiched between the LCM (Liquid Crystal Module), the BEF (Brightness Enhancement Film) and the blue LED. Reprinted with permission from Reference [133]. Copyright 2012, SID DIGEST.

In this geometry, the LED excitation is spread over the entire area, which enables all three colors to produce a white light back-illumination across the panel with high quality, uniformity and increased device lifetime. However, the QDs have to be appropriately functionalized for the efficient inclusion in polymeric matrices and the QDEF has to be sandwiched between two layers for preventing the moisture and oxygen that could adversely affect the QDs emission efficiency. The resulting device exceeds the color output and efficiencies of OLED, producing 50\% more colors within the NTSC 1953 color gamut and with emission properties invariable over 30,000 working hours, even if the production cost is still high [134]. Following the same strategy, Luo and colleagues demonstrated the possibility of increasing the color gamut over 120\% NTSC in CIE 1931 color space and 140\% NTSC in CIE 1976 color space, as depicted in Figure 13, using $\mathrm{CdS}_{\mathrm{x}} \mathrm{Se}_{1-\mathrm{x}} / \mathrm{ZnS}$ core-shell QDs from Cytodiagnostics. The particle size was between $5.5 \mathrm{~nm}$ and $6.5 \mathrm{~nm}$ to modify the emission wavelength [117]. These results exceed the data obtained for the displays produced by Samsung [116] and Nanosys [133], covering respectively $104.3 \%$ and $109 \%$ NTSC in CIE 1931 color space.

Instead of using a flat and large film doped with QDs, QD Vision developed a new product having the QDs integrated in a LED array placed in the panel edge. This allows a reduction to $1 \%$ of QDs with respect to the amount used in QDEF film. In parallel, they are also working for replacing organic material in OLED with inorganic QDs for direct light generation with better definition of R-G-B emission wavelength. In this case, by suspending QDs in appropriate solvents and polymeric matrices, it will be possible to develop innovative processes based on direct printing maintaining higher emission efficiencies with respect to organic molecules [132]. 

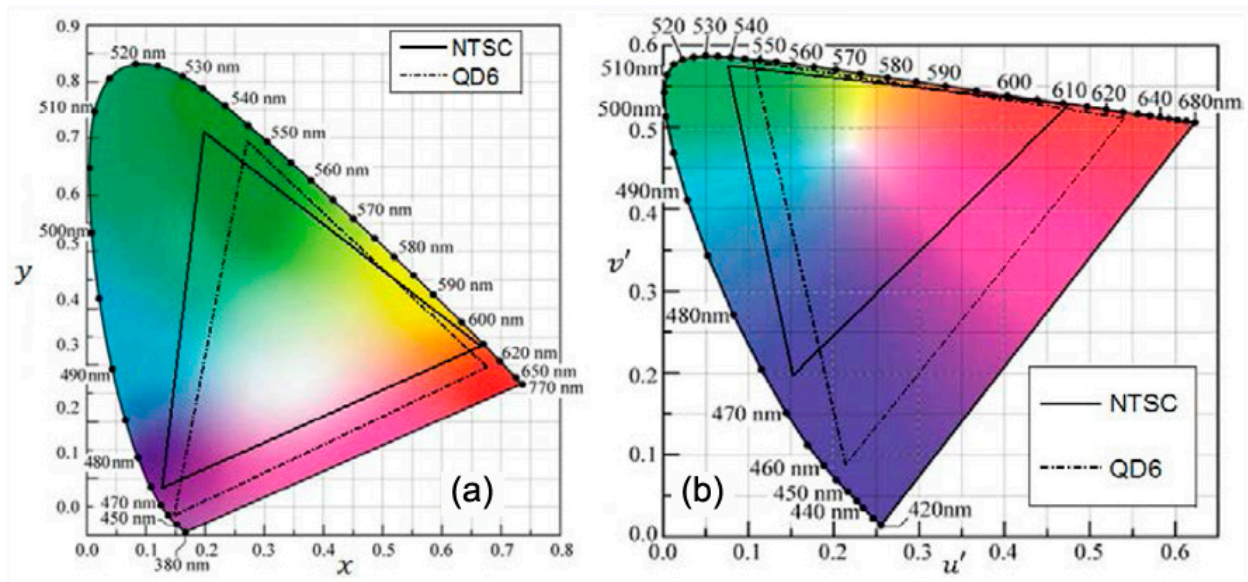

Figure 13. (a) Color primaries of a QDs sample (named QD6) as well as NTSC standard in CIE 1931 color space; and (b) Color primaries of QD 6 and NTSC standard in CIE 1976 color space. Reprinted with permission from Reference [117]. Copyright 2013, OSA.

Inorganic QDs have also been largely studied as emitting materials in electrically pumped light emitting devices (QLED). Many works have explored the possibility of producing single color QLEDs, reaching the best performances with II-IV group visible emitting QDs [135]. However, QLEDs still exhibit low efficiency if compared to other inorganic or organic LED. This is mainly due to the misalignment between the QDs energy levels and the levels of the coupled charge transport layers. Indeed, the misalignment with the hole transport layer (HTL) prevents the hole injection between the QDs and the HTL, favoring the adverse effect of exciton quenching. Many approaches have been proposed, including the use of a sensitizer that transfers the excitation energy to the QDs via Förster resonance energy transfer [136] or the use of an inorganic electron transport layer (ETL) and an organic HTL. With the latter configuration, the highest external quantum efficiencies are found to be $10.7 \%$, $14.5 \%, 20.5 \%$ for blue, green, red QLED respectively $[135,137]$. Stability remains a well-known issue for the blue and green QLEDs.

Meanwhile, the inclusion of all three primary colors into one device is still posing critical issues regarding the processing of the final device. Various strategies are explored using also different processing techniques. Kim et al. fabricated a full color QDs display using a solvent-free transfer microprinting method where microstripes of single red, green, and blue emitting QDs are used to sequential transfer of QDs to a pixelated display panel (see Figure 14). Thanks to the elastic behavior of PDMS stamp, this printing method can transfer QDs onto flexible substrates, giving exciting opportunities for scaling up the process to a roll-to-roll system [138].

Other deposition processes involve full solution processing architectures, using the spin casting technique for the deposition of single colour QDs in each subpixel $[137,139]$, or the deposition of multiple stacked layers by combining solution/vacuum methods [140]. Recently, Lee at al. demonstrated all-solution-processed fabrication of a highly efficient, bright full-color QLED, where RGB QDs-mixed emitting multilayer is sandwiched with poly(9-vinlycarbazole) and ZnO NPs layer acting respectively as HTL and ETL counterparts (see Figure 15). In Lee's work high-quality fluorescent blue $(\mathrm{CdZnS} / \mathrm{ZnS})$, green $(\mathrm{CdZnSeS} / \mathrm{ZnS})$, and red $(\mathrm{CdSeS} / \mathrm{ZnS})$ QDs were mixed together, obtaining a color gamut of about $126 \%$ relative to CIE standard [21]. 
a)

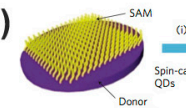
sincerting
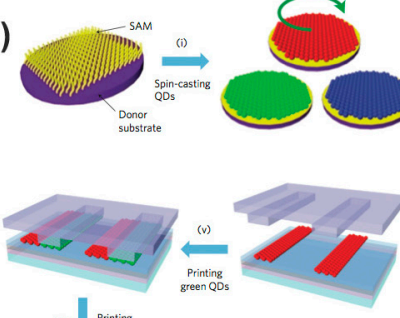

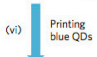

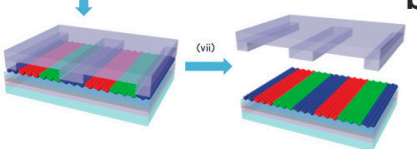

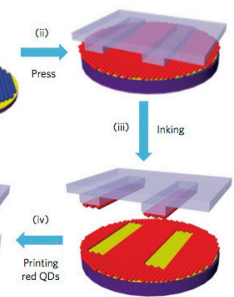

b)

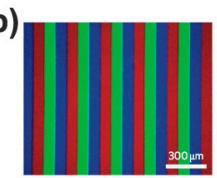

c)

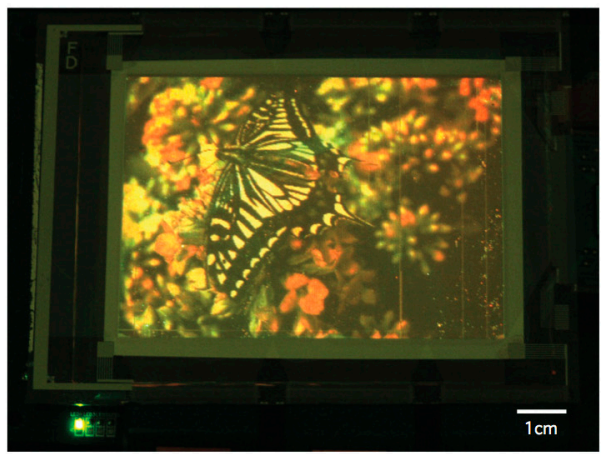

Figure 14. (a) Transfer printing process for micropatterning of quantum dots; (b) Fluorescence image of the RGB QD microstripes onto the glass substrate; (c) Electroluminescence image of a 4-inch full-color QD display using a HIZO TFT backplane with a $320 \times 240$ pixel array. Reprinted with permission from Reference [138]. Copyright 2011, Macmillan Publishers Ltd.

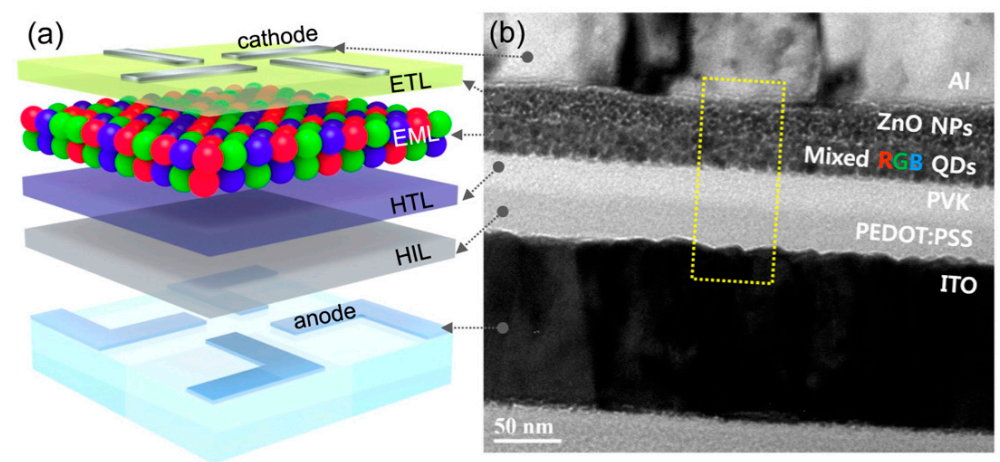

Figure 15. (a) Device structure and (b) cross-sectional TEM micrograph of all-solution processed full-color QLED. Reprinted with permission from Reference [21]. Copyright 2015, American Chemical Society.

Most of the studies on QLED report on the application of quite simple QDs based on a core/shell structure, having a II-VI group core and $\mathrm{ZnS}$ as shell. To further improve the device performance, important challenges need to be addressed for a widespread use, such as the proper inclusion of QDs in a shell to prevent excitation or heat damage, new encapsulants must be developed and a better engineering of the energy level alignment across all interfaces to achieve a higher external quantum efficiency. Finally, one of the biggest challenges is related to the use of an eco-friendlier emitting material with respect to Cd-based nanostructures. In this context, some structures based on III-V InP [141] and $\operatorname{In}_{x} Z n_{x} P$ QDs [142] have been studied, although critical issues regarding the complete surface passivation and lattice mismatch at the core/shell interface for such systems still remain under investigation.

\section{Conclusions and Outlook}

In recent years, much progress has been made in understanding the structure and dynamics of semiconductor QDs with a view towards their envisaged applications in photonics, optoelectronics, medical diagnostics and therapy. Smart engineering of NC heterostructures, known as core/shell QDs, has emerged as the most successful strategy for gaining control on detrimental processes such as carrier trapping at defects and non-radiative exciton decay, particularly Auger recombination.

In this review, paper we have provided experimental support to the idea that suitably engineered core/graded-shell QDs, prepared by exerting atom-by-atom control on the growth of monolayers of 
varying composition, provides the best results for maintaining the exceptionally favorable linear and non-linear optical properties, photoluminescence and optical gain, while keeping the synthesis facile and producing QDs well suited for light emitting applications.

Among the numerous prospective applications of semiconductor NCs in photonic technologies, some of which have already reached the marketplace, solid-state laser emitters can greatly profit from QDs as efficient gain materials. This goal will only be achieved if QDs-doped matrices that preserve their favorable photophysical characteristics and are chemically and photo-chemically stable are realized. Progress towards fabricating low threshold, solution processed DFB lasers that are optically pumped using one- and two-photon absorption processes have already provided proof-of-concept, with ample space for improvement by optimization of components and design.

The use of QDs in display devices is gradually gaining its own market share by competing effectively with the LCD and OLED technologies. The high color purity and solution-processable nature of QDs are particularly appealing for such a market. The exploitation of the exceptional photoluminescence properties of QDs for LCD backlighting has already advanced to commercial levels. The color output and efficiency exceed those of OLED, enabling us to approach the full color gamut according to the standard NTSC requirements. The next big challenge is to develop the electroluminescence properties of QD to a similar state. All the exceptional light emitting properties are retained for QLED devices, which provides them with great perspectives for the development of next generation display technologies. However, further efforts are required to progress in our understanding of energy and charge transfer processes in QD films to ensure higher external efficiencies and long term stabilities. The choice of QDs to be used in QLEDs must consider high photoluminescence in dispersed solutions as a starting criterion, which means low trap densities and reduction of Auger recombination. However, in QD films the role of recombination at surface traps is amplified because energy transfer brings into play the trapping at all the QDs visited by energy migration. The formation of charged QDs (i.e., trions) that amplify the AR, the effect of the electric field applied to bias the device, the efficient coupling with the hole and electron transport layers are other factors that must be taken into account. Here too, the continuous progress in producing semiconductor NCs with different architectures (chiefly core/shell ones) and embodying multiple functionalities is providing exciting opportunities for the fundamental understanding of optical processes at the nanoscale and for engineering nanostructures for application in display and energy technologies.

Acknowledgments: Financial support by the Ministry of Education and Research through the projects PRIN-2012T9XHH7, FIRB-RBPR05JH2P_001 and FIRB-RBAP11X42L_002 is gratefully acknowledged. J.J.J. would like to acknowledge funding through the The Australian Research Council through the Grant DP110105341. F.T. and I.F. acknowledge the granting of "Assegno di Ricerca Senior" (Repertorio 76-2012 and 156-2014) by the University of Padova.

Author Contributions: All authors contributed to scientific discussion and critical revision of the article.

Conflicts of Interest: The authors declare no conflict of interest.

\section{References}

1. Supran, G.J.; Shirasaki, Y.; Song, K.W.; Caruge, J.M.; Kazlas, P.T.; Coe-Sullivan, S.; Andrew, T.L.; Bawendi, M.G.; Bulovic, V. QLEDs for displays and solid-state lighting. MRS Bull. 2013, 38, 703-711. [CrossRef]

2. Frecker, T.; Bailey, D.; Arzeta-Ferrer, X.; McBride, J.; Rosenthal, S.J. Review-quantum dots and their application in lighting, displays, and biology. ECS J. Solid State Sci. Technol. 2016, 5, R3019-R3031. [CrossRef]

3. Erdem, T.; Demir, H.V. Color science of nanocrystal quantum dots for lighting and displays. Nanophotonics Berlin 2013, 2, 57-81. [CrossRef]

4. Hollingsworth, J.A. Nanoscale engineering facilitated by controlled synthesis: From structure to function. Coord. Chem. Rev. 2014, 263, 197-216. [CrossRef]

5. Hines, D.A.; Kamat, P.V. Recent advances in quantum dot surface chemistry. ACS Appl. Mater. Inter. 2014, 6, 3041-3057. [CrossRef] [PubMed] 
6. Peterson, M.D.; Cass, L.C.; Harris, R.D.; Edme, K.; Sung, K.; Weiss, E.A. The role of ligands in determining the exciton relaxation dynamics in semiconductor quantum dots. Annu. Rev. Phys. Chem. 2014, 65, 317-339. [CrossRef] [PubMed]

7. Bae, W.K.; Brovelli, S.; Klimov, V.I. Spectroscopic insights into the performance of quantum dot light-emitting diodes. MRS Bull. 2013, 38, 721-730. [CrossRef]

8. Steckel, J.S.; Ho, J.; Hamilton, C.; Xi, J.Q.; Breen, C.; Liu, W.H.; Allen, P.; Coe-Sullivan, S. Quantum dots: The ultimate down-conversion material for LCD displays. J. Soc. Inf. Display 2015, 23, 294-305. [CrossRef]

9. Boles, M.A.; Ling, D.; Hyeon, T.; Talapin, D.V. The surface science of nanocrystals. Nat. Mater. 2016, 15, 141-153. [CrossRef] [PubMed]

10. Alvarado, S.R.; Guo, Y.; Ruberu, T.P.A.; Tavasoli, E.; Vela, J. Inorganic chemistry solutions to semiconductor nanocrystal problems. Coord. Chem. Rev. 2014, 263-264, 182-196. [CrossRef]

11. Klimov, V.I. Nanocrystals Quantum Dots, 2nd ed.; CRC Press: Boca Raton, FL, USA, 2010.

12. Kambhampati, P. Unraveling the the structure and dynamics of excitons in semiconductor quantum dots. Accounts Chem. Res. 2011, 44, 1-13. [CrossRef] [PubMed]

13. Chaudhuri, R.G.; Paria, S. Core/Shell nanoparticles: Classes, properties, synthesis mechanisms, characterization, and applications. Chem. Rev. 2012, 112, 2373-2433. [CrossRef] [PubMed]

14. Smith, A.M.; Nie, S.M. Semiconductor nanocrystals: Structure, properties, and band gap engineering. Accounts Chem. Res. 2010, 43, 190-200. [CrossRef] [PubMed]

15. Kim, J.Y.; Voznyy, O.; Zhitomirsky, D.; Sargent, E.H. 25th anniversary article: Colloidal quantum dot materials and devices: A quarter-century of advances. Adv. Mater. 2013, 25, 4986-5010. [CrossRef] [PubMed]

16. Jasieniak, J.; Califano, M.; Watkins, S.E. Size-dependent valence and conduction band-edge energies of semiconductor nanocrystals. ACS Nano 2011, 5, 5888-5902. [CrossRef] [PubMed]

17. Abécassis, B. Three-dimensional self-assembly of semiconducting colloidal nanocrystals: From fundamental forces to collective optical properties. ChemPhysChem 2016, 17, 618-631. [CrossRef] [PubMed]

18. Tessier, M.D.; Biadala, L.; Bouet, C.; Ithurria, S.; Abecassis, B.; Dubertret, B. Phonon line emission revealed by self-assembly of colloidal nanoplatelets. ACS Nano 2013, 7, 3332-3340. [CrossRef] [PubMed]

19. Guzelturk, B.; Olutas, M.; Delikanli, S.; Kelestemur, Y.; Erdem, O.; Demir, H.V. Nonradiative energy transfer in colloidal CdSe nanoplatelet films. Nanoscale 2015, 7, 2545-2551. [CrossRef] [PubMed]

20. Kim, J.-Y.; Kotov, N.A. Charge transport dilemma of solution-processed nanomaterials. Chem. Mater. 2014, 26, 134-152. [CrossRef]

21. Lee, K.H.; Han, C.Y.; Kang, H.D.; Ko, H.; Lee, C.; Lee, J.; Myoung, N.; Yim, S.Y.; Yang, H. Highly efficient, color-reproducible full-color electroluminescent devices based on red/green/blue quantum dot-mixed multilayer. ACS Nano 2015, 9, 10941-10949. [CrossRef] [PubMed]

22. Kairdolf, B.A.; Smith, A.M.; Stokes, T.H.; Wang, M.D.; Young, A.N.; Nie, S.M. Semiconductor quantum dots for bioimaging and biodiagnostic applications. Annu. Rev. Anal. Chem. 2013, 6, 143-162. [CrossRef] [PubMed]

23. Gur, I.; Fromer, N.A.; Geier, M.L.; Alivisatos, A.P. Air-stable all-inorganic nanocrystal solar cells processed from solution. Science 2005, 310, 462-465. [CrossRef] [PubMed]

24. Mews, A.; Zhao, J. Light-emitting diodes-A bright outlook for quantum dots. Nat. Photonics 2007, 1, 682-683. [CrossRef]

25. Malko, A.V.; Mikhailovsky, A.A.; Petruska, M.A.; Hollingsworth, J.A.; Htoon, H.; Bawendi, M.G.; Klimov, V.I. From amplified spontaneous emission to microring lasing using nanocrystal quantum dot solids. Appl. Phys. Lett. 2002, 81, 1303-1305. [CrossRef]

26. Mashford, B.S.; Stevenson, M.; Popovic, Z.; Hamilton, C.; Zhou, Z.Q.; Breen, C.; Steckel, J.; Bulovic, V.; Bawendi, M.; Coe-Sullivan, S.; et al. High-efficiency quantum-dot light-emitting devices with enhanced charge injection. Nat. Photonics 2013, 7, 407-412. [CrossRef]

27. Kambhampati, P. Hot exciton relaxation dynamics in semiconductor quantum dots: Radiationless transitions on the nanoscale. J. Phys. Chem. C 2011, 115, 22089-22109. [CrossRef]

28. Bullen, C.; Mulvaney, P. The effects of chemisorption on the luminescence of CdSe quantum dots. Langmuir 2006, 22, 3007-3013. [CrossRef] [PubMed]

29. Vasudevan, D.; Gaddam, R.R.; Trinchi, A.; Cole, I. Core-shell quantum dots: Properties and applications. J. Alloys Compd. 2015, 636, 395-404. [CrossRef] 
30. Chen, O.; Zhao, J.; Chauhan, V.P.; Cui, J.; Wong, C.; Harris, D.K.; Wei, H.; Han, H.S.; Fukumura, D.; Jain, R.K.; et al. Compact high-quality CdSe-CdS core-shell nanocrystals with narrow emission linewidths and suppressed blinking. Nat. Mater. 2013, 12, 445-451. [CrossRef] [PubMed]

31. Reiss, P.; Protiere, M.; Li, L. Core/shell semiconductor nanocrystals. Small 2009, 5, 154-168. [CrossRef] [PubMed]

32. Dennis, A.M.; Mangum, B.D.; Piryatinski, A.; Park, Y.-S.; Hannah, D.C.; Casson, J.L.; Williams, D.J.; Schaller, R.D.; Htoon, H.; Hollingsworth, J.A. Suppressed blinking and auger recombination in near-infrared type-II InP/CdS nanocrystal quantum dots. Nano Lett. 2012, 12, 5545-5551. [CrossRef] [PubMed]

33. Dalui, A.; Chakraborty, A.; Thupakula, U.; Khan, A.H.; Sengupta, S.; Satpati, B.; Sarma, D.D.; Dasgupta, I.; Acharya, S. Chemical tailoring of band offsets at the interface of ZnSe-CdS heterostructures for delocalized photoexcited charge carriers. J. Phys. Chem. C 2016, 120, 10118-10128. [CrossRef]

34. Pedetti, S.; Ithurria, S.; Heuclin, H.; Patriarche, G.; Dubertret, B. Type-II CdSe/CdTe core/crown semiconductor nanoplatelets. J. Am. Chem. Soc. 2014, 136, 16430-16438. [CrossRef] [PubMed]

35. Smith, A.M.; Mohs, A.M.; Nie, S. Tuning the optical and electronic properties of colloidal nanocrystals by lattice strain. Nat. Nano 2009, 4, 56-63. [CrossRef] [PubMed]

36. Lin, Q.; Song, B.; Wang, H.; Zhang, F.; Chen, F.; Wang, L.; Li, L.S.; Guo, F.; Shen, H. High-efficiency deep-red quantum-dot light-emitting diodes with type-II CdSe/CdTe core/shell quantum dots as emissive layers. J. Mater. Chem. C 2016, 4, 7223-7229. [CrossRef]

37. Kelestemur, Y.; Olutas, M.; Delikanli, S.; Guzelturk, B.; Akgul, M.Z.; Demir, H.V. Type-II colloidal quantum wells: CdSe/CdTe core/crown heteronanoplatelets. J. Phys. Chem. C 2015, 119, 2177-2185. [CrossRef]

38. Bang, J.; Park, J.; Lee, J.H.; Won, N.; Nam, J.; Lim, J.; Chang, B.Y.; Lee, H.J.; Chon, B.; Shin, J.; et al. ZnTe/ZnSe (core/shell) type-II quantum dots: Their optical and photovoltaic properties. Chem. Mater. 2010, 22, $233-240$. [CrossRef]

39. Ning, Z.; Tian, H.; Yuan, C.; Fu, Y.; Qin, H.; Sun, L.; Agren, H. Solar cells sensitized with type-II ZnSe-CdS core/shell colloidal quantum dots. Chem. Commun. 2011, 47, 1536-1538. [CrossRef] [PubMed]

40. Zhu, H.; Song, N.; Rodríguez-Córdoba, W.; Lian, T. Wave function engineering for efficient extraction of up to nineteen electrons from one CdSe/CdS quasi-type II quantum dot. J. Am. Chem. Soc. 2012, 134, 4250-4257. [CrossRef] [PubMed]

41. Smith, C.T.; Tyrrell, E.J.; Leontiadou, M.A.; Miloszewski, J.; Walsh, T.; Cadirci, M.; Page, R.; O’Brien, P.; Binks, D.; Tomić, S. Energy structure of CdSe/CdTe type II colloidal quantum dots-Do phonon bottlenecks remain for thick shells? Sol. Energy Mater. Sol. Cells 2016. [CrossRef]

42. Itzhakov, S.; Shen, H.; Buhbut, S.; Lin, H.; Oron, D. Type-II quantum-dot-sensitized solar cell spanning the visible and near-infrared spectrum. J. Phys. Chem. C 2013, 117, 22203-22210. [CrossRef]

43. Spanhel, L.; Haase, M.; Weller, H.; Henglein, A. Photochemistry of colloidal semiconductors. 20. Surface modification and stability of strong luminescing CdS particles. J. Am. Chem. Soc. 1987, 109, 5649-5655. [CrossRef]

44. Kortan, A.R.; Hull, R.; Opila, R.L.; Bawendi, M.G.; Steigerwald, M.L.; Carroll, P.J.; Brus, L.E. Nucleation and growth of CdSe on $\mathrm{ZnS}$ quantum crystallite seeds, and vice versa, in inverse micelle media. J. Am. Chem. Soc. 1990, 112, 1327-1332. [CrossRef]

45. Murray, C.B.; Norris, D.J.; Bawendi, M.G. Synthesis and characterization of nearly monodisperse CdE $(E=S$, Se, Te) semiconductor nanocrystallites. J. Am. Chem. Soc. 1993, 115, 8706-8715. [CrossRef]

46. Hines, M.A.; Guyot-Sionnest, P. Synthesis and characterization of strongly luminescing ZnS-capped CdSe nanocrystals. J. Phys. Chem. US 1996, 100, 468-471. [CrossRef]

47. Dabbousi, B.O.; RodriguezViejo, J.; Mikulec, F.V.; Heine, J.R.; Mattoussi, H.; Ober, R.; Jensen, K.F.; Bawendi, M.G. (CdSe)ZnS core-shell quantum dots: Synthesis and characterization of a size series of highly luminescent nanocrystallites. J. Phys. Chem. B 1997, 101, 9463-9475. [CrossRef]

48. Peng, X.G.; Schlamp, M.C.; Kadavanich, A.V.; Alivisatos, A.P. Epitaxial growth of highly luminescent CdSe/CdS core/shell nanocrystals with photostability and electronic accessibility. J. Am. Chem. Soc. 1997, 119, 7019-7029. [CrossRef]

49. Li, J.J.; Wang, Y.A.; Guo, W.Z.; Keay, J.C.; Mishima, T.D.; Johnson, M.B.; Peng, X.G. Large-scale synthesis of nearly monodisperse $\mathrm{CdSe} / \mathrm{CdS}$ core/shell nanocrystals using air-stable reagents via successive ion layer adsorption and reaction. J. Am. Chem. Soc. 2003, 125, 12567-12575. [CrossRef] [PubMed] 
50. Van Embden, J.; Jasieniak, J.; Mulvaney, P. Mapping the optical properties of CdSe/CdS heterostructure nanocrystals: The effects of core size and shell thickness. J. Am. Chem. Soc. 2009, 131, 14299-14309. [CrossRef] [PubMed]

51. Xie, R.G.; Kolb, U.; Li, J.X.; Basche, T.; Mews, A. Synthesis and characterization of highly luminescent CdSe-core CdS $/ \mathrm{Zn}_{0.5} \mathrm{Cd}_{0.5} \mathrm{~S} / \mathrm{ZnS}$ multishell nanocrystals. J. Am. Chem. Soc. 2005, 127, 7480-7488. [CrossRef] [PubMed]

52. Chen, Y.; Vela, J.; Htoon, H.; Casson, J.L.; Werder, D.J.; Bussian, D.A.; Klimov, V.I.; Hollingsworth, J.A. “Giant” multishell CdSe nanocrystal quantum dots with suppressed blinking. J. Am. Chem. Soc. 2008, 130, 5026-5027. [CrossRef] [PubMed]

53. Battaglia, D.; Li, J.J.; Wang, Y.J.; Peng, X.G. Colloidal two-dimensional systems: CdSe quantum shells and wells. Angew. Chem. Int. Ed. 2003, 42, 5035-5039. [CrossRef] [PubMed]

54. Li, J.J.; Tsay, J.M.; Michalet, X.; Weiss, S. Wavefunction engineering: From quantum wells to near-infrared type-II colloidal quantum dots synthesized by layer-by-layer colloidal epitaxy. Chem. Phys. 2005, 318, 82-90. [PubMed]

55. Zhan, H.J.; Zhou, P.J.; Pan, K.L.; He, T.; He, X.; Zhou, C.Y.; He, Y.N. One-pot aqueous-phase synthesis of ultra-small CdSe/CdS/CdZnS core-shell-shell quantum dots with high-luminescent efficiency and good stability. J. Nanopart. Res. 2013, 15. [CrossRef]

56. Washington Ii, A.L.; Strouse, G.F. Microwave synthesis of CdSe and CdTe nanocrystals in nonabsorbing alkanes. J. Am. Chem. Soc. 2008, 130, 8916-8922. [CrossRef] [PubMed]

57. Boldt, K.; Kirkwood, N.; Beane, G.A.; Mulvaney, P. Synthesis of highly luminescent and photo-stable, graded shell CdSe $/ \mathrm{Cd}_{\mathrm{x}} \mathrm{Zn}_{1-\mathrm{x}} \mathrm{S}$ nanoparticles by in situ alloying. Chem. Mater. 2013, 25, 4731-4738. [CrossRef]

58. Phillips, T.W.; Lignos, I.G.; Maceiczyk, R.M.; deMello, A.J.; deMello, J.C. Nanocrystal synthesis in microfluidic reactors: Where next? Lab Chip 2014, 14, 3172-3180. [CrossRef] [PubMed]

59. Nightingale, A.M.; deMello, J.C. Segmented flow reactors for nanocrystal synthesis. Adv. Mater. 2013, 25, 1813-1821. [CrossRef] [PubMed]

60. Toyota, A.; Nakamura, H.; Ozono, H.; Yamashita, K.; Uehara, M.; Maeda, H. Combinatorial synthesis of CdSe nanoparticles using microreactors. J. Phys. Chem. C 2010, 114, 7527-7534. [CrossRef]

61. Baek, J.; Allen, P.M.; Bawendi, M.G.; Jensen, K.F. Investigation of indium phosphide nanocrystal synthesis using a high-temperature and high-pressure continuous flow microreactor. Angew. Chem. Int. Ed. 2011, 50, 627-630. [CrossRef] [PubMed]

62. Kwon, B.-H.; Lee, K.G.; Park, T.J.; Kim, H.; Lee, T.J.; Lee, S.J.; Jeon, D.Y. Continuous in situ synthesis of $\mathrm{ZnSe} / \mathrm{ZnS}$ core/shell quantum dots in a microfluidic reaction system and its application for light-emitting diodes. Small 2012, 8, 3257-3262. [CrossRef] [PubMed]

63. Chen, C.J.; Chiang, R.K.; Huang, C.Y.; Lien, J.Y.; Wang, S.L. Thiol treatment to enhance photoluminescence and electroluminescence of CdSe/CdS core-shell quantum dots prepared by thermal cycling of single source precursors. RSC Adv. 2015, 5, 9819-9827. [CrossRef]

64. Klimov, V.I. Multicarrier interactions in semiconductor nanocrystals in relation to the phenomena of auger recombination and carrier multiplication. Annu. Rev. Condens. Matter Phys. 2014, 5, 285-316. [CrossRef]

65. Tschirner, N.; Lange, H.; Schliwa, A.; Biermann, A.; Thomsen, C.; Lambert, K.; Gomes, R.; Hens, Z. Interfacial alloying in CdSe/CdS heteronanocrystals: A Raman spectroscopy analysis. Chem. Mater. 2012, 24, 311-318. [CrossRef]

66. Todescato, F.; Minotto, A.; Signorini, R.; Jasieniak, J.J.; Bozio, R. Investigation into the heterostructure interface of CdSe-based core-shell quantum dots using surface-enhanced raman spectroscopy. ACS Nano 2013, 7, 6649-6657. [CrossRef] [PubMed]

67. Grumbach, N.; Capek, R.K.; Tilchin, E.; Rubin-Brusilovski, A.; Yang, J.F.; Ein-Eli, Y.; Lifshitz, E. Comprehensive route to the formation of alloy interface in core/shell colloidal quantum dots. J. Phys. Chem. C 2015, 119, 12749-12756. [CrossRef]

68. Fairclough, S.M.; Tyrrell, E.J.; Graham, D.M.; Lunt, P.J.B.; Hardman, S.J.O.; Pietzsch, A.; Hennies, F.; Moghal, J.; Flavell, W.R.; Watt, A.A.R.; et al. Growth and characterization of strained and alloyed type-II ZnTe/ZnSe core-shell nanocrystals. J. Phys. Chem. C 2012, 116, 26898-26907. [CrossRef]

69. Garcia-Santamaria, F.; Brovelli, S.; Viswanatha, R.; Hollingsworth, J.A.; Htoon, H.; Crooker, S.A.; Klimov, V.I. Breakdown of volume scaling in auger recombination in CdSe/CdS heteronanocrystals: The role of the core-shell interface. Nano Lett. 2011, 11, 687-693. [CrossRef] [PubMed] 
70. Javaux, C.; Mahler, B.; Dubertret, B.; Shabaev, A.; Rodina, A.V.; Efros, A.L.; Yakovlev, D.R.; Liu, F.; Bayer, M.; Camps, G.; et al. Thermal activation of non-radiative auger recombination in charged colloidal nanocrystals. Nat. Nanotechnol. 2013, 8, 206-212. [CrossRef] [PubMed]

71. Klimov, V.I.; Mikhailovsky, A.A.; McBranch, D.W.; Leatherdale, C.A.; Bawendi, M.G. Quantization of multiparticle auger rates in semiconductor quantum dots. Science 2000, 287, 1011-1013. [CrossRef] [PubMed]

72. Kharchenko, V.A.; Rosen, M. Auger relaxation processes in semiconductor nanocrystals and quantum wells. J. Lumin. 1996, 70, 158-169. [CrossRef]

73. Cragg, G.E.; Efros, A.L. Suppression of auger processes in confined structures. Nano Lett. 2010, 10, $313-317$. [CrossRef] [PubMed]

74. Saha, A.; Chellappan, K.V.; Narayan, K.S.; Ghatak, J.; Datta, R.; Viswanatha, R. Near unity quantum yield in semiconducting nanostructures: Structural understanding leading to energy efficient applications. J. Phys. Chem. Lett. 2013, 4, 3544-3549. [CrossRef]

75. Orfield, N.J.; McBride, J.R.; Keene, J.D.; Davis, L.M.; Rosenthal, S.J. Correlation of atomic structure and photoluminescence of the same quantum dot: Pinpointing surface and internal defects that inhibit photoluminescence. ACS Nano 2015, 9, 831-839. [CrossRef] [PubMed]

76. Mahler, B.; Spinicelli, P.; Buil, S.; Quelin, X.; Hermier, J.P.; Dubertret, B. Towards non-blinking colloidal quantum dots. Nat. Mater. 2008, 7, 659-664. [CrossRef] [PubMed]

77. Kim, S.; Fisher, B.; Eisler, H.J.; Bawendi, M. Type-II quantum dots: CdTe/CdSe (core/shell) and CdSe/ZnTe (core/shell) heterostructures. J. Am. Chem. Soc. 2003, 125, 11466-11467. [CrossRef] [PubMed]

78. Wang, L.; Tian, Y.M.; Okuhata, T.; Tamai, N. Charge transfer dynamics and Auger recombination of CdTe/CdS core/shell quantum dots. J. Phys. Chem. C 2015, 119, 17971-17978. [CrossRef]

79. Oron, D.; Kazes, M.; Banin, U. Multiexcitons in type-II colloidal semiconductor quantum dots. Phys. Rev. B 2007, 75. [CrossRef]

80. Htoon, H.; Hollingsworth, J.A.; Dickerson, R.; Klimov, V.I. Effect of zero- to one-dimensional transformation on multiparticle Auger recombination in semiconductor quantum rods. Phys. Rev. Lett. 2003, 91. [CrossRef] [PubMed]

81. Pan, L.Y.; Zhang, Y.L.; Wang, H.Y.; Liu, H.; Luo, J.S.; Xia, H.; Zhao, L.; Chen, Q.D.; Xu, S.P.; Gao, B.R.; et al. Hierarchical self-assembly of CdTe quantum dots into hyperbranched nanobundles: Suppression of biexciton auger recombination. Nanoscale 2011, 3, 2882-2888. [CrossRef] [PubMed]

82. Todescato, F.; Fortunati, I.; Gardin, S.; Garbin, E.; Collini, E.; Bozio, R.; Jasieniak, J.J.; Della Giustina, G.; Brusatin, G.; Toffanin, S.; et al. Soft-lithographed up-converted distributed feedback visible lasers based on CdSe-CdZnS-ZnS quantum dots. Adv. Funct. Mater. 2012, 22, 337-344. [CrossRef]

83. Minotto, A.; Todescato, F.; Fortunati, I.; Signorini, R.; Jasieniak, J.J.; Bozio, R. Role of core-shell interfaces on exciton recombination in CdSe-Cd $\mathrm{Zn}_{1-\mathrm{x}} \mathrm{S}$ quantum dots. J. Phys. Chem. C 2014, 118, 24117-24126. [CrossRef]

84. Zhong, X.H.; Han, M.Y.; Dong, Z.L.; White, T.J.; Knoll, W. Composition-tunable $\mathrm{Zn}_{\mathrm{x}} \mathrm{Cd}_{1-\mathrm{x}}$ Se nanocrystals with high luminescence and stability. J. Am. Chem. Soc. 2003, 125, 8589-8594. [CrossRef] [PubMed]

85. Jones, M.; Lo, S.S.; Scholes, G.D. Quantitative modeling of the role of surface traps in CdSe/CdS/ZnS nanocrystal photoluminescence decay dynamics. Proc. Natl. Acad. Sci. USA 2009, 106, 3011-3016. [CrossRef] [PubMed]

86. Park, Y.-S.; Bae, W.K.; Baker, T.; Lim, J.; Klimov, V.I. Effect of Auger recombination on lasing in heterostructured quantum dots with engineered core/shell interfaces. Nano Lett. 2015, 15, 7319-7328. [CrossRef] [PubMed]

87. Klimov, V.I.; Ivanov, S.A.; Nanda, J.; Achermann, M.; Bezel, I.; McGuire, J.A.; Piryatinski, A. Single-exciton optical gain in semiconductor nanocrystals. Nature 2007, 447, 441-446. [CrossRef] [PubMed]

88. Klimov, V.I. Mechanisms for photogeneration and recombination of multiexcitons in semiconductor nanocrystals: Implications for lasing and solar energy conversion. J. Phys. Chem. B 2006, 110, 16827-16845. [CrossRef] [PubMed]

89. Garcia-Santamaria, F.; Chen, Y.F.; Vela, J.; Schaller, R.D.; Hollingsworth, J.A.; Klimov, V.I. Suppressed auger recombination in "giant" nanocrystals boosts optical gain performance. Nano Lett. 2009, 9, 3482-3488. [CrossRef] [PubMed]

90. Grim, J.Q.; Christodoulou, S.; Di Stasio, F.; Krahne, R.; Cingolani, R.; Manna, L.; Moreels, I. Continuous-wave biexciton lasing at room temperature using solution-processed quantum wells. Nat. Nanotechnol. 2014, 9 , 891-895. [CrossRef] [PubMed] 
91. Kazes, M.; Oron, D.; Shweky, I.; Banin, U. Temperature dependence of optical gain in CdSe/ZnS quantum rods. J. Phys. Chem. C 2007, 111, 7898-7905. [CrossRef]

92. Zhang, C.F.; Zhang, F.; Cheng, A.; Kimball, B.; Wang, A.Y.; Xu, J. Frequency upconverted lasing of nanocrystal quantum dots in microbeads. Appl. Phys. Lett. 2009, 95. [CrossRef]

93. Guzelturk, B.; Kelestemur, Y.; Olutas, M.; Delikanli, S.; Demir, H.V. Amplified spontaneous emission and lasing in colloidal nanoplatelets. ACS Nano 2014, 8, 6599-6605. [CrossRef] [PubMed]

94. Smirnova, T.N.; Sakhno, O.V.; Yezhov, P.V.; Kokhtych, L.M.; Goldenberg, L.M.; Stumpe, J. Amplified spontaneous emission in polymer-CdSe/ZnS-nanocrystal DFB structures produced by the holographic method. Nanotechnology 2009, 20. [CrossRef] [PubMed]

95. Signorini, R.; Fortunati, I.; Todescato, F.; Gardin, S.; Bozio, R.; Jasieniak, J.J.; Martucci, A.; Della Giustina, G.; Brusatin, G.; Guglielmi, M. Facile production of up-converted quantum dot lasers. Nanoscale 2011, 3, 4109-4113. [CrossRef] [PubMed]

96. Wang, Y.; Ta, V.D.; Gao, Y.; He, T.C.; Chen, R.; Mutlugun, E.; Demir, H.V.; Sun, H.D. Stimulated emission and lasing from CdSe/CdS/ZnS core-multi-shell quantum dots by simultaneous three-photon absorption. Adv. Mater. 2014, 26, 2954-2961. [CrossRef] [PubMed]

97. Patel, R.K.; Trichet, A.A.P.; Coles, D.M.; Dolan, P.R.; Fairclough, S.M.; Leontiadou, M.A.; Tsang, S.C.E.; Binks, D.J.; Jang, E.; Jang, H.; et al. Gain spectroscopy of solution-based semiconductor nanocrystals in tunable optical microcavities. Adv. Optical Mater. 2016, 4, 285-290. [CrossRef]

98. Chen, Y.; Herrnsdorf, J.; Guilhabert, B.; Zhang, Y.; Watson, I.M.; Gu, E.; Laurand, N.; Dawson, M.D. Colloidal quantum dot random laser. Opt. Express 2011, 19, 2996-3003. [CrossRef] [PubMed]

99. Gies, C.; Florian, M.; Gartner, P.; Jahnke, F. The single quantum dot-laser: Lasing and strong coupling in the high-excitation regime. Opt. Express 2011, 19, 14370-14388. [CrossRef] [PubMed]

100. Strauf, S.; Jahnke, F. Single quantum dot nanolaser. Laser Photonics Rev. 2011, 5, 607-633. [CrossRef]

101. Boyd, R.W. Nonlinear Optics; Accademic Press: New York, NY, USA, 1992.

102. Signorini, R.; Ferrante, C.; Pedron, D.; Zerbetto, M.; Cecchetto, E.; Slaviero, M.; Fortunati, I.; Collini, E.; Bozio, R.; Abbotto, A.; et al. Effective two-photon absorption cross section of heteroaromatic quadrupolar dyes: Dependence on measurement technique and laser pulse characteristics. J. Phys. Chem. A 2008, 112, 4224-4234. [CrossRef] [PubMed]

103. Fortunati, I.; Signorini, R.; Bozio, R.; Jasieniak, J.J.; Antonello, A.; Martucci, A.; Della Giustina, G.; Brusatin, G.; Guglielmi, M. CdSe core-shell nanoparticles as active materials for up-converted emission. J. Phys. Chem. C 2011, 115, 3840-3846. [CrossRef]

104. Scott, R.; Achtstein, A.W.; Prudnikau, A.; Antanovich, A.; Christodoulou, S.; Moreels, I.; Artemyev, M.; Woggon, U. Two photon absorption in II-VI semiconductors: The influence of dimensionality and size. Nano Lett. 2015, 15, 4985-4992. [CrossRef] [PubMed]

105. Fortunati, I.; Gardin, S.; Todescato, F.; Signorini, R.; Bozio, R.; Jasieniak, J.J.; Martucci, A.; Giustina, G.D.; Brusatin, G.; Guglielmi, M.; et al. One- and two-photon pumped DFB laser based on semiconductor quantum dots embedded in a sol-gel matrix. In Biophotonics: Spectroscopy, Imaging, Sensing, and Manipulation; Bartolo, D.B., Collins, J., Eds.; Springer: Dordrecht, The Netherlands, 2011; pp. 415-416.

106. Jasieniak, J.; Pacifico, J.; Signorini, R.; Chiasera, A.; Ferrari, M.; Martucci, A.; Mulvaney, P. Luminescence and amplified stimulated emission in CdSe-ZnS-nanocrystal-doped $\mathrm{TiO}_{2}$ and $\mathrm{ZrO}_{2}$ waveguides. Adv. Funct Mater. 2007, 17, 1654-1662. [CrossRef]

107. Brusatin, G.; Della Giustina, G. Hybrid organic-inorganic sol-gel materials for micro and nanofabrication. J. Sol. Gel Sci. Technol. 2011, 60, 299-314. [CrossRef]

108. Holzer, W.; Penzkofer, A.; Pertsch, T.; Danz, N.; Brauer, A.; Kley, E.B.; Tillmann, H.; Bader, C.; Horhold, H.H. Corrugated neat thin-film conjugated polymer distributed-feedback lasers. Appl. Phys. B Lasers O 2002, 74, 333-342. [CrossRef]

109. Ye, C.; Wang, J.; Lo, D. Two-photon-pumped distributed feedback zirconia waveguide lasers. Appl. Phys. B Lasers O 2004, 78, 539-541. [CrossRef]

110. Xing, G.; Liao, Y.; Wu, X.; Chakrabortty, S.; Liu, X.; Yeow, E.K.L.; Chan, Y.; Sum, T.C. Ultralow-threshold two-photon pumped amplified spontaneous emission and lasing from seeded CdSe/CdS nanorod heterostructures. ACS Nano 2012, 6, 10835-10844. [CrossRef] [PubMed] 
111. Guzelturk, B.; Kelestemur, Y.; Gungor, K.; Yeltik, A.; Akgul, M.Z.; Wang, Y.; Chen, R.; Dang, C.; Sun, H.; Demir, H.V. Stable and low-threshold optical gain in CdSe/CdS quantum dots: An all-colloidal frequency up-converted laser. Adv. Mater. 2015, 27, 2741-2746. [CrossRef] [PubMed]

112. Commission Internationale de l'Eclairage Proceedings Ed.; Cie 1931; Cambridge University Press: Cambridge, UK, 1931.

113. Cie 1976. Available online: http://www.Iso.Org/obp/ui/-iso:Std:Iso:11664:-5:Ed-1:V1:En.1976 (accessed on 5 August 2016).

114. Jou, J.H.; Kumar, S.; Agrawal, A.; Li, T.H.; Sahoo, S. Approaches for fabricating high efficiency organic light emitting diodes. J. Mater. Chem. C 2015, 3, 2974-3002. [CrossRef]

115. Zhu, R.D.; Luo, Z.Y.; Chen, H.W.; Dong, Y.J.; Wu, S.T. Realizing Rec. 2020 color gamut with quantum dot displays. Opt. Express 2015, 23, 23680-23693. [CrossRef] [PubMed]

116. Jang, E.; Jun, S.; Jang, H.; Llim, J.; Kim, B.; Kim, Y. White-light-emitting diodes with quantum dot color converters for display backlights. Adv. Mater. 2010, 22, 3076-3080. [CrossRef] [PubMed]

117. Luo, Z.Y.; Chen, Y.; Wu, S.T. Wide color gamut LCD with a quantum dot backlight. Opt. Express 2013, 21, 26269-26284. [CrossRef] [PubMed]

118. Kathirgamanathan, P.; Bushby, L.M.; Kumaraverl, M.; Ravichandran, S.; Surendrakumar, S. Electroluminescent organic and quantum dot LEDs: The state of the art. J. Disp. Technol. 2015, 11, 480-493. [CrossRef]

119. Qian, L.; Zheng, Y.; Xue, J.G.; Holloway, P.H. Stable and efficient quantum-dot light-emitting diodes based on solution-processed multilayer structures. Nat. Photonics 2011, 5, 543-548. [CrossRef]

120. Kim, H.C.; Yoon, C.; Song, Y.-G.; Kim, Y.-J.; Lee, K. Enhancing performance of quantum dot-based light emitting diodes by using poly(methyl methacrylate)@ quantum dot hybrid particles. Korean J. Chem. Eng. 2015, 32, 563-566. [CrossRef]

121. Chung, W.; Park, K.; Yu, H.J.; Kim, J.; Chun, B.-H.; Kim, S.H. White emission using mixtures of CdSe quantum dots and pmma as a phosphor. Opt. Mater. 2010, 32, 515-521. [CrossRef]

122. Wang, X.; Li, W.; Sun, K. Stable efficient CdSe/CdS/ZnS core/multi-shell nanophosphors fabricated through a phosphine-free route for white light-emitting-diodes with high color rendering properties. J. Mater. Chem. 2011, 21, 8558-8565. [CrossRef]

123. Liras, M.; Quijada-Garrido, I.; Palacios-Cuesta, M.; Munoz-Durieux, S.; Garcia, O. Acetyl protected thiol methacrylic polymers as effective ligands to keep quantum dots in luminescent standby mode. Polym. Chem. 2014, 5, 433-442. [CrossRef]

124. Zhu, L.; Xu, L.; Wang, J.; Yang, S.; Wang, C.-F.; Chen, L.; Chen, S. Macromonomer-induced cdte quantum dots toward multicolor fluorescent patterns and white LEDs. RSC Adv. 2012, 2, 9005-9010. [CrossRef]

125. Kwak, S.K.; Yoo, T.W.; Kim, B.-S.; Lee, S.M.; Lee, Y.S.; Park, L.S. White LED packaging with layered encapsulation of quantum dots and optical properties. Mol. Cryst. Liquid Cryst. 2012, 564, 33-41. [CrossRef]

126. Li, F.; Li, W.-N.; Fu, S.-Y.; Xiao, H.-M. Formulating CdSe quantum dots for white light-emitting diodes with high color rendering index. J. Alloys Compd. 2015, 647, 837-843. [CrossRef]

127. Han, J.; Bong, J.; Lim, T.; Lee, K.-H.; Yang, H.; Ju, S. Water repellent spray-type encapsulation of quantum dot light-emitting diodes using super-hydrophobic self-assembled nanoparticles. Appl. Surf. Sci. 2015, 353, 338-341. [CrossRef]

128. Chen, L.; Zhang, C.; Du, Z.; Li, H.; Zhang, L.; Zou, W. Synthesis of poly(n-butyl methacrylate)-(glycidyl methacrylate) block copolymer and its compatibilization at the interface of the QD/epoxy nanocomposite for white LED encapsulation. RSC Adv. 2015, 5, 65184-65191. [CrossRef]

129. Xie, B.; Hu, R.; Luo, X. Quantum dots-converted light-emitting diodes packaging for lighting and display: Status and perspectives. J. Electr. Packag. 2016, 138, 020803-020803. [CrossRef]

130. Coe-Sullivan, S.; Liu, W.H.; Allen, P.; Steckel, J.S. Quantum dots for LED downconversion in display applications. ECS J. Solid State Sci. Technol. 2013, 2, R3026-R3030. [CrossRef]

131. Van Derlofske, J.F.; Hillis, J.M.; Lathrop, A.; Wheatley, J.; Thielen, J.; Benoit, G. Illuminating the value of larger color gamuts for quantum dot displays. SID Symp. Dig. Tech. Pap. 2014, 45, 237-240. [CrossRef]

132. Patel, P. Quantum dots are behind new displays. IEEE Spectrum 2012, 8, 14-17. [CrossRef]

133. Chen, J.; Hardev, V.; Hartlove, J.; Hofler, J.; Lee, E. A high-efficiency wide-color-gamut solid-state backlight system for LCDs using quantum dot enhancement film. SID Symp. Dig. Tech. Pap. 2012, 43, 895-896. [CrossRef]

134. Chen, J.; Hardev, V.; Yurek, J. Quantum-dot displays: Giving LCDs a competitive edge through color. Inf. Display 2013, 29, 4-13. 
135. Yang, Y.X.; Zheng, Y.; Cao, W.R.; Titov, A.; Hyvonen, J.; Manders, J.R.; Xue, J.G.; Holloway, P.H.; Qian, L. High-efficiency light-emitting devices based on quantum dots with tailored nanostructures. Nat. Photonics 2015, 9, 259-266. [CrossRef]

136. Siboni, H.Z.; Sadeghimakki, B.; Sivoththaman, S.; Aziz, H. Very high brightness quantum dot light-emitting devices via enhanced energy transfer from a phosphorescent sensitizer. ACS Appl. Mater. Interfaces 2015, 7, 25828-25834. [CrossRef] [PubMed]

137. Dai, X.L.; Zhang, Z.X.; Jin, Y.Z.; Niu, Y.; Cao, H.J.; Liang, X.Y.; Chen, L.W.; Wang, J.P.; Peng, X.G. Solution-processed, high-performance light-emitting diodes based on quantum dots. Nature 2014, 515, 96-99. [CrossRef] [PubMed]

138. Kim, T.H.; Cho, K.S.; Lee, E.K.; Lee, S.J.; Chae, J.; Kim, J.W.; Kim, D.H.; Kwon, J.Y.; Amaratunga, G.; Lee, S.Y.; et al. Full-colour quantum dot displays fabricated by transfer printing. Nat. Photonics 2011, 5, 176-182. [CrossRef]

139. Yang, X.Y.; Ma, Y.Y.; Mutlugun, E.; Zhao, Y.B.; Leck, K.S.; Tan, S.T.; Demir, H.V.; Zhang, Q.Y.; Du, H.J.; Sun, X.W. Stable, efficient, and all-solution-processed quantum dot light-emitting diodes with double-sided metal oxide nanoparticle charge transport layers. ACS Appl. Mater. Interfaces 2014, 6, 495-499. [CrossRef] [PubMed]

140. Bae, W.K.; Lim, J.; Lee, D.; Park, M.; Lee, H.; Kwak, J.; Char, K.; Lee, C.; Lee, S. R/G/B/natural white light thin colloidal quantum dot-based light-emitting devices. Adv. Mater. 2014, 26, 6387-6393. [CrossRef] [PubMed]

141. Park, J.P.; Kim, T.H.; Kim, S.-W. Highly stable Cd free quantum dot/polymer composites and their WLED application. Dyes Pigments 2016, 127, 142-147. [CrossRef]

142. Pietra, F.; De Trizio, L.; Hoekstra, A.W.; Renaud, N.; Prato, M.; Grozema, F.C.; Baesjou, P.J.; Koole, R.; Manna, L.; Houtepen, A.J. Tuning the lattice parameter of $\operatorname{In}_{\mathrm{x}} \mathrm{Zn}_{\mathrm{y}} \mathrm{P}$ for highly luminescent lattice-matched core/shell quantum dots. ACS Nano 2016, 10, 4754-4762. [CrossRef] [PubMed]

(C) 2016 by the authors; licensee MDPI, Basel, Switzerland. This article is an open access article distributed under the terms and conditions of the Creative Commons Attribution (CC-BY) license (http://creativecommons.org/licenses/by/4.0/). 